\title{
Markers to measure immunomodulation in human nutrition intervention studies $\dagger$
}

\author{
Ruud Albers ${ }^{1}$, Jean-Michel Antoine ${ }^{2}$, Raphaëlle Bourdet-Sicard ${ }^{2}$, Philip C. Calder ${ }^{3}$, Michael Gleeson ${ }^{4}$, \\ Bruno Lesourd ${ }^{5}$, Sonia Samartín ${ }^{6}$, Ian R. Sanderson ${ }^{7}$, Jan Van Loo $^{8}$, F. Willem Vas Dias ${ }^{9}$ and Bernhard Watzl ${ }^{10}$ \\ ${ }^{1}$ Unilever Health Institute, PO Box 114, NL 3130 AC Vlaardingen, The Netherlands \\ ${ }^{2}$ Danone Vitapole - Nutrivaleur, Route Départementale 128, F-91767 Palaiseau cedex, France \\ ${ }^{3}$ University of Southampton, Institute of Human Nutrition, Faculty of Medicine, Bassett Crescent East, Southampton SO16 7PX, UK \\ ${ }^{4}$ Loughborough University, School of Sport \& Exercise Sciences, Loughborough LE11 3TU, UK \\ ${ }^{5}$ Hôpital Universitaire de Clermont-Ferrand, Service Soins de Suite, Route de Châteaugay BP 56, F-63118 Cebazat, France \\ ${ }^{6}$ ILSI Europe, 83 Av. E. Mounier Box 6, B-1200 Brussels, Belgium \\ ${ }^{7}$ Research Centre in Gastroenterology, Institute of Cell and Molecular Science, Barts and the London, Queen Mary School of Medicine \\ and Dentistry, Turner Street, London E1 2AD, UK \\ ${ }^{8}$ Raffinerie Tirlemontoise, Orafti, Aandorenstraat 1, B-3300 Tienen, Belgium \\ ${ }^{9}$ Seven Seas Ltd, Hedon Road, Marfleet, Hull HU9 5NJ, UK \\ ${ }^{10}$ Federal Research Centre for Nutrition and Food, Institute of Nutritional Physiology, Haid-und-Neu-Strasse, D-76131 Karlsruhe, \\ Germany
}

(Received 19 January 2005 - Accepted 18 February 2005)

\begin{abstract}
Normal functioning of the immune system is crucial to the health of man, and diet is one of the major exogenous factors modulating individual immunocompetence. Recently, nutrition research has focused on the role of foods or specific food components in enhancing immune system responsiveness to challenges and thereby improving health and reducing disease risks. Assessing diet-induced changes of immune function, however, requires a thorough methodological approach targeting a large spectrum of immune system parameters. Currently, no single marker is available to predict the outcome of a dietary intervention on the resistance to infection or to other immune system-related diseases. The present review summarises the immune function assays commonly used as markers in human intervention studies and evaluates their biological relevance (e.g. known correlation with clinically relevant endpoints), sensitivity (e.g. within- and between-subject variation), and practical feasibility. Based on these criteria markers were classified into three categories with high, medium or low suitability. Vaccine-specific serum antibody production, delayed-type hypersensitivity response, vaccine-specific or total secretory IgA in saliva and the response to attenuated pathogens, were classified as markers with high suitability. Markers with medium suitability include natural killer cell cytotoxicity, oxidative burst of phagocytes, lymphocyte proliferation and the cytokine pattern produced by activated immune cells. Since no single marker allows conclusions to be drawn about the modulation of the whole immune system, except for the clinical outcome of infection itself, combining markers with high and medium suitability is currently the best approach to measure immunomodulation in human nutrition intervention studies. It would be valuable to include several immune markers in addition to clinical outcome in future clinical trials in this area, as there is too little evidence that correlates markers with global health improvement.
\end{abstract}

Immune function: Marker: Diet: Human studies: Infections

\section{Task and objectives}

The major function of the immune system is to protect the body against infectious diseases. The immune system can be divided into innate and adaptive immunity. The immune system operates at the systemic as well as at the local level, which includes the mucosal tissue such as in the upper airways and the gut. A fundamental characteristic of the immune system is that it involves multiple, functionally differing cell types, which permit a large variety of defence mechanisms. Assessing the status of the immune system and its functionality therefore requires a thorough methodological approach targeting a large spectrum of immune

Abbreviations: APC, antigen-presenting cell; CD, cluster of differentiation; DTH, delayed-type hypersensitivity; HLA, human leucocyte antigen; IFN, interferon; ILSI, International Life Sciences Institute; LPS, lipopolysaccharide; NK, natural killer; PBMC, peripheral blood mononuclear cell; PEM, protein-energy malnutrition; PG, prostaglandin; TH, T helper; TLR, toll-like receptor; URTI, upper respiratory-tract infection.

$\dagger$ A draft version of this review was extensively discussed with experts from the fields of nutrition, (clinical) immunology, mucosal immunology, gastroenterology and immunotoxicology during a Workshop, organised by the European branch of the International Life Sciences Institute (ILSI Europe), on 'Markers to Assess the Impact of Nutrition on Immune Function in Man' held in Vienna, Austria, 9-11 June 2004.

* Corresponding author: Dr S. Samartin, fax +32 276200 44, email publications@ilsieurope.be 
system parameters. However, currently it is not possible to predict the cumulative effects of several small changes in immune system parameters on host resistance (Keil et al. 2001).

Nutrition is known to affect the immune system and thereby modulates resistance to infection (Chandra, 1991; Scrimshaw \& SanGiovanni, 1997). At the single nutrient level, it has been shown that all immune functions rely on an adequate nutrient supply in order to function properly. Human trials have provided evidence that supplementation with single nutrients, as well as qualitative changes in certain macronutrients, affect specific immune functions even in well-nourished individuals. A major focus of current research is the role of specific food components or foods in enhancing immune system responsiveness to challenge with the aim of improving health and reducing disease risk. Target groups are the general population, as well as certain vulnerable groups with particular sensitivity towards infectious diseases.

The aim of the present review is to summarise existing knowledge on the quality of the markers commonly used to assess immune functions in healthy human subjects. This includes a description of the standard immune function assays used in human studies, their specificity, normal range and dynamics of change, their statistical validation, and their known correlation with clinical endpoints. The majority of human studies have looked at changes in systemic immunity and only a few studies have tried to measure the effect of dietary interventions on the gut immune system. Because experimental data indicate that diet affects the immune system associated with the intestinal tract (Roller et al. 2004), the review also includes current methods applied at the intestinal level. Most of the immune markers considered can be used in various subgroups of the population (infants, elderly, etc.) but the appropriate selection of markers depends on the objectives of individual studies (clinical studies, field work. etc.). The overall aim is to identify an appropriate set of relevant markers of immune functions that could be used to measure enhanced immune functions, including those of the gut immune system, in response to a nutritional intervention and to substantiate suitable markers for improved resistance to infection. The present review paper was prepared by the Expert Group on 'Nutrients and Immune Resistance to Infections' of the Nutrition and Immunity in Man Task Force of the European branch of the International Life Sciences Institute (ILSI Europe). A draft version of this review was extensively discussed with experts from the fields of nutrition, (clinical) immunology, mucosal immunology, gastroenterology and immunotoxicology during the ILSI Europe Workshop 'Markers to Assess the Impact of Nutrition on Immune Function in Man' held in Vienna, Austria, 9-11 June 2004.

\section{Immune functions and health}

Resistance to infection is strongly influenced by the effectiveness of the immune system in protecting the host against pathogenic micro-organisms. A comprehensive description of the human immune system can be found in many textbooks (e.g. Janeway et al. 2005). Immune function is influenced by genetic as well as environmental factors and thus there is some degree of variability in resistance to infection within the normal healthy adult population. Resistance to specific infections is also affected by previous exposure to the disease-causing pathogen or inoculation with vaccines used for immunisation. Vaccines contain dead or attenuated pathogens that trigger immune responses including the development of specific memory without eliciting symptoms of disease that are associated with inoculation by wild-type pathogens.

Age is a critical factor in resistance to infection. Antigenspecific cellular and humoral immunity are central to the adaptive immune responses generated in the human adult. In contrast, the very young rely primarily on innate immunity although this component of the immune system is not as functionally developed in young children as it is in adults. Although many previous studies have demonstrated a marked decline in several aspects of immune function in the elderly, it is now recognised that some immune responses do not decline and can even increase with advancing age (Lesourd et al. 2002). Nowadays the influence of ageing on the immune system is generally described as a progressive occurrence of dysregulation, rather than as a general decline in function. Indeed, it has also been shown that many decreased immune responses that were previously attributed to the ageing process are actually linked to other factors such as poor nutritional status or an ongoing disease that is not clinically apparent (Lesourd et al. 2002).

The sex of the individual also affects immune function. In females, oestrogens and progesterone modulate immune function (Paavonen, 1994) and thus immunity is influenced by the menstrual cycle and pregnancy (Haus \& Smolensky, 1999). Consequently, sex-based differences in responses to infection, trauma and sepsis are evident (Beery, 2003). Evaluation of immune responses must take into account sex differences in the study population as well as the menstrual cycle and hormonal treatment. Women are generally more resistant to viral infections and tend to have more autoimmune diseases than men (Beery, 2003). Oestrogens are generally immune-enhancing, whereas androgens, including testosterone, exert suppressive effects on both humoral and cellular immune responses. In females, there is increased expression of some cytokines in peripheral blood and vaginal fluids during the follicular phase of the menstrual cycle and with use of hormonal contraceptives (Brabin, 2002). In the luteal phase of the menstrual cycle, blood leucocyte counts are higher than in the follicular phase and the immune response is shifted towards a $\mathrm{T}$ helper (TH) 2-type response (Faas et al. 2000). In pregnancy, elevated levels of progesterone appear to suppress cell-mediated immune function and TH1 cytokine production and to enhance humoral immunity and TH2 cytokine production (Wilder, 1998).

Psychological stress is thought to influence immune function through autonomic nerves innervating lymphoid tissue and by stress hormone-mediated alteration of immune cell functions (Cohen et al. 1991). Stress hormones (particularly catecholamines and glucocorticoids) are potent modulators of immune function. Chronic psychological stress also appears to lower salivary IgA levels, evidenced by a transient decrease in the levels of salivary IgA in students under academic examination stress (Jemmott et al. 1983). The literature concerning the relationship between psychological stress and immunodepression is inconsistent, largely due to the numerous variables that need to be controlled. However, Cohen et al. (1991) carried out a well-controlled study (including controls for education, shared housing and personality differences) in which subjects were intentionally exposed to one of five respiratory viruses via nasal drops. The results indicated that psychological stress is associated with an increased risk of infection independent of the possibility of transmission, the 
strain of administered virus and habitual physical activity. Psychological stress may also modify immune responses through the adoption of coping behaviours, e.g. increased alcohol consumption or smoking. Elevated levels of stress hormones also occur during strenuous exercise and it is well recognised that acute bouts of exercise cause a temporary depression of various aspects of immune function (e.g. neutrophil oxidative burst, lymphocyte proliferation, monocyte MHC class II expression) that lasts about 3 to $24 \mathrm{~h}$ after exercise depending on the intensity and duration of the exercise bout (Gleeson \& Bishop, 1999). Periods of intensified training (over-reaching) lasting $7 \mathrm{~d}$ or more result in chronically depressed immune function and several surveys (e.g. Peters \& Bateman, 1983; Nieman et al. 1990; Heath et al. 1991) indicate that sore throats and flu-like symptoms are more common in endurance athletes than in the general population.

It is well established that the general nutritional status of an individual modulates his or her immune functions. Both overnutrition that results in obesity (Samartin \& Chandra, 2001) and undernutrition (Chandra, 1991; Scrimshaw \& SanGiovanni, 1997) affect functions of innate and acquired immunity detrimentally. Further, obesity (BMI $>30 \mathrm{~kg} / \mathrm{m}^{2}$ ) can be associated with chronic inflammation, resulting in increased plasma concentrations of C-reactive protein (CRP), IL-6, TNF- $\alpha$ and plasminogen activator inhibitor-1 (Dandona et al. 2004).

Particular aspects of the habitual diet including fat and protein intakes, multivitamin and mineral supplements and alcohol consumption exert a significant influence on immune function. Deficiencies of specific micronutrients are associated with an impaired immune response and with an increased susceptibility to infectious disease. If a nutrient supplement corrects an existing deficiency in an adult, then it is likely that a benefit to immune function will be seen. Indeed, many human and animal studies have demonstrated that adding the deficient micronutrient back to the diet will restore immune function and resistance to infection (Calder \& Kew, 2002). What is far less clear is whether increasing the intakes of specific micronutrients above those recommended will improve immune function in a healthy well-nourished individual. There is also a danger of excessive supplementation of the diet with individual micronutrients. Excessive intakes of some micronutrients (e.g. vitamin $\mathrm{E}, \mathrm{Fe}$ and $\mathrm{Zn}$ ) impair immune function and increase susceptibility to infection (Chandra, 1984; Bogden et al. 1990; Sherman, 1992). Thus, for many micronutrients there is a limited range of optimum intake, with levels above or below this resulting in impaired immune function and/or other health problems (Calder \& Kew, 2002).

Infectious diseases can affect the status of several nutrients in the body, thus setting up a vicious circle of undernutrition, compromised immunity and recurrent infection. Undernutrition is not a problem that is restricted to poor or developing countries. Undernutrition exists in developed countries especially among the elderly, premature babies, individuals with eating disorders, alcoholics and patients with certain diseases. Malnutrition was the leading cause of acquired immune deficiency before the appearance of the HIV and poor nutrition is also a major factor contributing to the progression of HIV infection.

In addition, several diseases that exist among the apparently well-nourished population have a strong immunological component. Examples of such diseases include asthma, atherosclerosis, cancer, Crohn's disease, myasthenia gravis, multiple sclerosis, rheumatoid arthritis, systemic lupus erythematosus and food allergies, and it is now well recognised that the course of some of these can be influenced by diet. For some of these diseases, symptoms may be caused or aggravated by an inappropriately activated immune system. Although a primary function of the immune function is to destroy pathogenic micro-organisms, it can also damage body tissues. Usually the inflammation and tissue destruction that are associated with the mechanisms used to eradicate a pathogen are acceptable to the host and do not cause significant impairment of host function. However, in several diseases (e.g. rheumatoid arthritis) the tissue destruction by the activated immune system is substantial, long-lasting and harmful. It is because of the potentially damaging effects of the immune cells on body tissues that the system is very tightly regulated. Failure of these regulatory mechanisms can result in the full might of the immune system being inappropriately directed against the body's own tissues and in the development of chronic inflammatory or autoimmune diseases. Clearly, attempts to stimulate immune function by nutritional means are inappropriate in these conditions. The suppression of inappropriate immune activity may be desirable and there is some evidence that the anti-inflammatory and immunosuppressive effects of long-chain $n-3$ PUFA may be of use as a therapy for chronic inflammation and for disorders that involve an inappropriately activated immune response (Calder \& Field, 2002).

\section{Changes in immune function during life and their significance in adults, infants, the elderly and exercising people}

\section{Healthy adults}

The introduction of an infectious agent into the body initiates an inflammatory response that augments that of the immune system. Acute inflammation increases local blood flow in the infected area and this coupled with augmented vascular permeability facilitates the entry of leucocytes and plasma proteins into the infected tissue. The immune response itself varies according to the nature of the infectious agent (parasitic, bacterial, fungal, viral) but a general response pattern is evident. Conserved molecular patterns on microbes are recognised by toll-like receptors (TLR) on macrophages and initiate intracellular signalling pathways that result in induction of co-stimulatory molecule expression and cytokine production. TLR appear to play an essential role in the activation of both innate and adaptive immunity (Schnare et al. 2001). Following ingestion of the micro-organism by the phagocytic macrophage, enzymes and oxidising agents are released from within the macrophage. The foreign proteins normally found on the micro-organism's surface are processed by the macrophage and incorporated into its own cell surface and are presented alongside MHC class II proteins. The antigen can now be presented to the other cellular immune components. TH cells (characterised by the expression of cluster of differentiation (CD) 4 on their surface) coordinate the response via TH1 and TH2 cytokine release to activate other immune cells. TH1 activation primarily promotes the actions of cytotoxic T cells, macrophages and non-specific natural killer (NK) cells which are responsible for cell-mediated immunity and are effective in the elimination of intracellular pathogens. TH1 cells can also stimulate the production of IgG1 and IgG3 by B cells. TH2 activation results in proliferation and stimulation of $\operatorname{IgG} 4$ and $\operatorname{IgE}$ production by B cells. Binding of the immunoglobulin to a specific antigen forms an antibody-antigen complex. This represents the 
humoral (fluid) immune response and is an effective defence against extracellular pathogens present in the body fluids.

Whether humoral or cell-mediated immunity will dominate depends largely on the type of cytokines that are released by the activated TH cells. Cell-mediated immunity depends on a so-called TH1 profile of cytokines, including particularly interferon (IFN)- $\gamma$ and IL-2. These cytokines activate macrophages and induce killer mechanisms that involve cytotoxic T cells. A TH2 profile includes mainly IL-4, IL-5 and IL-13, which are necessary for promotion of humoral immunity, IgE-mediated allergic reactions and activation of potentially tissue-damaging eosinophils. IL-4 and IL-13 primarily drive B cell differentiation to antibody production, while IL-5 stimulates and primes eosinophils (Cummings et al. 2004).

In recent years great efforts have been made to elucidate the mechanisms involved in the induction and regulation of a polarised cytokine profile characterising activated TH cell subsets. There is particularly great interest in the role of antigen-presenting cells (APC) in shaping the phenotypes of naïve T cells during their initial priming, partly because the differential expression level of various co-stimulatory molecules on activated and matured APC may exert a decisive impact (Liew, 2002). Thus, interaction of the CD28 receptor on T cells with CD80 on APC appears to favour TH1 differentiation, whereas interaction with CD86 appears to favour the TH2 phenotype. Certain cytokines secreted by the TH1 and TH2 cells that evolve act in an autocrine and reciprocally inhibitory fashion: IL- 4 promotes TH2 cell expansion and limits proliferation of TH1 cells, whereas IFN$\gamma$ enhances growth of TH1 cells but decreases TH2 cell development. In fact, the cytokine microenvironment clearly represents a potent determinant of TH1/TH2 polarisation, with IL-4 and IL-12 as the initiating key factors, these being derived principally from innate immune responses during $\mathrm{T}$ cell priming. Activated APC are the main source of IL-12, whereas an early burst of IL-4 may come from NK cells, mast cells, basophils or already matured bystander TH2 cells (Liew, 2002).

Altogether, exogenous stimuli such as pathogen-derived products and the maturational stage of APC, as well as genetic factors, will influence differentiation into the $\mathrm{TH} 1$ or $\mathrm{TH} 2$ phenotype in addition to complex interactions between antigen dose, T-cell receptor engagement and MHC antigen affinities. Influential antigenic properties include the nature of the antigen, with bacteria and viruses promoting $\mathrm{TH} 1$ cell differentiation and helminths the $\mathrm{TH} 2$ subset. $\mathrm{TH} 2$ differentiation also appears to be promoted by small soluble proteins characteristic of allergens.

Although it is somewhat of an oversimplification, the TH1 response can be seen as the major promoter of cell-mediated reactions that provide effective defence against intracellular pathogens (i.e. viruses and bacteria that can enter host cells or are phagocytosed). In contrast, the $\mathrm{TH} 2$ response primarily activates humoral immunity and the antibodies produced are only effective against pathogens in the extracellular fluids. As mentioned previously, TH1- and TH2-type responses are cross-regulatory, and the TH1/TH2 cytokine balance is also influenced by regulatory TH3 cells (Maloy \& Powrie 2001), which may secrete the suppressive cytokines IL-10 and transforming growth factor (TGF)$\beta$ and thus exert a dampening effect directly on innate immune mechanisms (Maloy et al. 2003).

In healthy normal adults, small decreases or increases in single selected markers of immune function may not be clinically important. There are two main reasons for this. First, there is a considerable degree of redundancy in the immune system, such that a small change in the functional capacity of one component of immune function may be compensated for by a change in the functional capacity of another. Second, there may be a certain amount of excess capacity in some aspects of immune function, particularly for those functions that are assessed using in vitro challenges using a high concentration of stimulant. Thus, it cannot be stated with any degree of certainty that small increases in one or more aspects of immune function will alter an individual's susceptibility to infection. Indeed for many aspects of immune function (e.g. blood neutrophil count and oxidative burst activity), it is not even known if the normal variation seen in the healthy adult population is a factor that influences the ability to fight infections. A more substantial increase in one or more aspects of immune function is probably more likely to reduce infection risk, although, of course, infection risk also depends on the degree of exposure to pathogens and the experience of previous exposure. However, for some immune cell functions a sufficiently large variation or change has been related to improved host defence. For example, some studies indicate that susceptibility to infections and cancer is greater in individuals who possess low NK cell activity compared with individuals with moderate to high NK cell activity (Levy et al. 1991; Imai et al. 2000; Ogata et al. 2001). Increasing several aspects of immune function would be expected to convey a more effective immune protection than an increase in just one aspect of immune function. It should be borne in mind that the relationship between a specific aspect of immune function and intake of a specific nutrient will not be the same for all immune cell functions. Indeed, it is entirely possible that the intake of a particular nutrient that produces optimum function in one aspect of immunity might result in sub-optimum function in another. Hence, it is important that studies on the effects of foods or food components on immunity measure a wide range of different immune markers. Ultimately, the real test of the efficacy of a food or food component that claims to improve immune function is a change in the incidence of infectious episodes or the severity or duration of symptoms of infection as this is the outcome of greatest clinical significance. When this can be confirmed, the measurement of a change in one or more aspects of immune function may provide information on the likely mechanism of the dietary intervention.

\section{Infants (paediatric immunology)}

The newborn child is immunologically competent. For example, the paediatric immune system handles infection and responds appropriately to immunisation. However, while many of the immune mechanisms that are present in the adult are also found in the child, there are a number of differences. These differences are due to two main interrelated factors. The first is the development of the immune system: certain aspects of the adaptive and innate immune systems are not fully functional at birth and develop thereafter. The second is a consequence of the low exposure to antigen until after birth. Thus, instruction of the acquired immune system, by definition, is incomplete at birth.

The present section highlights only important aspects of the paediatric immune system; for greater coverage, the reader is referred to larger texts (Spirer et al. 1993; Wolf, 2004). Innate immune mechanisms in infants are similar to those of adults because they do not require instruction. Nevertheless, there are 
some differences in innate immunity during ontogeny shown in species other than man.

Of the various components of the immune system that change after birth, the functions of the B lymphocyte lineage show the greatest alterations. Ig levels in the circulation of the newborn infant are low, apart from IgG transferred in utero from the maternal circulation. IgA is almost undetectable and IgM levels are also low, but do increase rapidly with an antigenic challenge such as neonatal infections. IgM levels above $0.2 \mathrm{mg} / \mathrm{ml}$ in cord blood suggest a congenital infection.

Because cord blood is easily obtained, the immune system in the immediate newborn period has been well described. Of the mononuclear cells in human cord blood, $80 \%$ are T lymphocytes, $10 \%$ are $\mathrm{B}$ cells and $10 \%$ are monocytes. The $\mathrm{T}$ lymphocytes express a range of cytokines that are similar to that of a $\mathrm{TH} 2$ response. Only during the first year of life does the predominant response of the T cell become that of a TH1. The development of the thymus and lymphoid tissue follows a pattern quite dissimilar to that of any other human organ. Most organs have their greatest period of growth in the early neonatal period with decreasing rates of growth thereafter. Organs that are dependent on puberty, such as those necessary for reproduction and growth, have an increase soon after the end of the first decade of life. The lymphoid system, however, increases in size faster than the body until around 7 years of age. It then becomes much smaller, reaching adult levels by the age of 12 years. These large increases in lymphoid tissue are the cause of well-recognised changes in the child such as large tonsils and adenoids (occasionally giving rise to problems with the upper airway) and also an increase in lymphoid nodules seen throughout the intestine at endoscopy.

The childhood period is also that in which most immunisations are given. The use of immunisations has revolutionised the practice of childhood medicine. The adequate response to immunisations has resulted in the virtual eradication and/or elimination of serious sequelae from measles, polio, whooping cough and Haemophilus infections.

\section{Elderly}

Ageing is associated with important but variable changes in immune responses. Some immune responses, such as blood $\mathrm{IgG}$ or IgA levels, lymphocyte proliferation and TH1 responses, decline with ageing, while others, such as prostaglandin (PG) $\mathrm{E}_{2}$ production or TH2 responses, increase (Lesourd et al. 2002). These changes have been reported to be due to either hormonal modifications throughout life (i.e. decline in thymic hormones after puberty) or to accumulating antigenic pressure during the life span. These changes are nowadays described as a progressive occurrence of immune dysregulation that leads to decreased cellmediated immune responses and relatively preserved antibody responses. Aged individuals are more sensitive to intracellular infections than younger adults (Pawelec et al. 2002). In addition, non-specific immunity appears to be less affected by the ageing process but induces a longer inflammatory process in the elderly.

Cell-mediated immune responses decline with ageing. Decline in thymic functions leads to a progressive decline in CD45RA (naïve) $\mathrm{T}$ cell subsets. Simultaneously $\mathrm{CD} 2^{+} \mathrm{CD} 3^{-}$subsets (NK cells) increase, showing another example of inverse evolution of immune responses (here cell subsets) with age.

Antigenic pressure throughout life leads to increases in memory T cells (many of which express CD45RO) and a decrease in naïve $\mathrm{T}$ cells (many of which express CD45RA; Cossarizza et al. 1992). Both changes affect $\mathrm{T}$ cell functions with a progressive decline in both lymphocyte proliferation and IL-2 synthesis, which are strongly associated with higher prevalence of infectious diseases in most elderly persons, although those selected for extreme good health (e.g. using the SENIEUR protocol; Ligthart et al. 1984) show similar levels of T cell proliferation and IL-2 production as healthy young people. Thus, these changes are less important in the very healthy elderly (self-sufficient, freeliving with no apparent disease and no decline in cognitive functions) in whom they are significant only at very old age $(>90$ years). However, they occur sooner in the less healthy frail elderly, indicating that disease-associated decreased immune responses play an important role in the decline in cell-mediated immunity. This may be more important than the ageing process per se (Mazari \& Lesourd, 1998). Ageing is also associated with a decline in $\mathrm{CD}^{+}$cytotoxic $\mathrm{T}$ cells while the $\mathrm{CD} 4^{+}$ subset seems to be preserved as long as nutritional status is 'normal'. However, an inverted CD4:CD8 ratio due to an increase in the number of dysfunctional CD8 cells predominantly specific for cytomegalovirus epitopes is commonly observed in the very elderly and is predictive of incipient mortality (Pawelec et al. 2004). The TH1:TH2 ratio also declines with age and this has been related to accumulation of antigenic pressure throughout life (Cakman et al. 1996). These changes may explain the decline in $\mathrm{CD}^{+}$cell cytotoxic functions, which are TH1-dependent, and the relatively preserved $\mathrm{B}$ cell functions, which are TH2-dependent. However, decreased numbers of B cells also contribute to predicting incipient mortality in longitudinal studies. These changes may be quantified by measurement of in vitro cytokine release in lymphocyte cultures (i.e. decreases in TH1 cytokines such as IL-2 or increases in TH2 cytokines such as IL-4, IL-5 or IL-13). Nevertheless, contradictory results have been reported: for example, IFN- $\gamma$, a TH1 cytokine, has been reported to decrease, to remain unchanged or even to increase with ageing. Therefore, this general picture of $\mathrm{TH} 1 / \mathrm{TH} 2$ changes with ageing must still be viewed with some caution. For an excellent survey of the available data and pitfalls in their generation and interpretation, see Gardner \& Murasko (2002).

Antibody responses, encompassing $\mathrm{Ig} \mathrm{A}, \mathrm{IgG}$ or IgM responses after antigenic exposure (such as vaccination), are comparable in healthy elderly and younger adults. This may be related to the relative increase in $\mathrm{TH} 2$ responses with ageing that boost $\mathrm{IgA}$ and $\operatorname{IgG}$ production. Nevertheless, even though the antibody level does not change or even rises, antibody affinity declines with ageing. This has been associated with progressive decreases in the $\mathrm{CD}^{-} \mathrm{B}$ cell subset that is responsible for the high-affinity antibody while the $\mathrm{CD}^{+}$subset, which produces lower-affinity antibody, increases (Weksler, 1995). In addition, a high level of anti-idiotype antibody production has been described after inoculation with tetanus vaccine in aged individuals (Arreaza et al. 1993). These changes in antibody affinity may partly explain the lower protection sometimes observed after vaccination in healthy aged individuals.

Monocyte functions, including antigen processing and presentation as well as cytokine release (TNF- $\alpha$, IL-1, IL-6) are unchanged or even increased in the elderly (Lesourd, 1999). High resting serum IL-6 levels have often been reported in the apparently healthy elderly population, a phenomenon that has never been described in younger healthy individuals. This has been linked to a permanent activation of monocytes, which is 
associated with higher $\mathrm{PGE}_{2}$ and free radical production (Hayek et al. 1997). Such a phenomenon is detrimental for cell-mediated immunity since $\mathrm{PGE}_{2}$ is a strong inhibitor of $\mathrm{T}$ cell functions, particularly in aged persons. This represents an important age-related dysregulation of the immune system. Inflammatory processes are always of long duration in the elderly. In fact, a longer period of hormone secretion, as measured by the rise in the plasma cortisol level (Sapolsky et al. 1986), after stress challenge, is a general phenomenon in aged rats. These longer inflammatory processes lead to higher use of body nutrient reserves in stressed aged individuals. This is particularly dangerous in the elderly person since he or she is no longer able to completely restore depleted nutritional body reserves, particularly muscle proteins (Lesourd, 1999). Therefore any stress, through a longer activation of the immune system, pushes the elderly towards undernutrition and a more fragile physical state.

Undernutrition exerts a strong effect on immune responses in the elderly. Protein-energy malnutrition (PEM) is always associated with lower immune responses and this is observed for all types of immunity: cell-mediated immunity, antibody responses as well as innate immunity. This effect is strongly correlated with the severity of PEM. Undernourished elderly individuals are therefore at high risk for infectious diseases. The effects of micronutrient deficiencies are more often observed in aged individuals than in younger people (Lesourd, 2000). Nutritional supplementation, whether macronutrient energy supplements in PEM or micronutrient supplements in micronutrient deficiency states, usually leads to increased immune responses (Lesourd et al. 1998). In addition, while vitamin E deficiency is not commonly reported in the elderly, cell-mediated immune responses are increased after vitamin E supplementation (Meydani et al. 1997) showing that vitamin $E$ needs may be higher in aged individuals than the current recommendations specify. Vitamin E supplementation is associated with decreases in $\mathrm{PGE}_{2}$ and free radical production by monocytes, showing that the permanent activation of monocytes is detrimental to immune responses in the elderly.

The dysregulation of immune responses observed in the elderly is probably due to cumulative pressure on the immune system throughout life, driving $\mathrm{T}$ cell differentiation towards a limited repertoire of dysfunctional $\mathrm{T}$ cell memory responses. This, coupled with decreased thymic output of naïve $\mathrm{T}$ cells, as well as age-associated compromised function of naïve cells produced earlier in life, results in increased susceptibility of the elderly to challenge by new pathogens. Undernutrition, whatever its type, adds another detrimental factor to immune responses, the elderly being particularly susceptible to nutritional factors. Protection against permanently increased free radical production may be an effective way to boost immune responses in the elderly.

\section{Exercise}

Athletes engaged in heavy training programmes, particularly those involved in endurance events, appear to be more susceptible than the sedentary population to infection. For example, according to some surveys (e.g. Peters \& Bateman 1983; Nieman et al. 1990; Heath et al. 1991) sore throats and flu-like symptoms are more common in athletes than in the general population and, once infected, colds may last for longer in athletes. There is some convincing evidence that this increased susceptibility to infection arises due to a depression of immune system function (for detailed reviews see Shephard, 1997; Gleeson \& Bishop, 1999; Mackinnon, 1999).

The circulating numbers and functional capacities of leucocytes may be decreased by repeated bouts of intense prolonged exercise. The reason is probably related to increased levels of stress hormones during exercise and entry into the circulation of less mature leucocytes from the bone marrow. Falls in the blood concentration of glutamine have also been suggested as a possible cause of the immunodepression associated with heavy training, although the evidence for this is less compelling. Inflammation caused by muscle damage may be another factor. Also, during exercise there is an increased production of reactive oxygen species and some immune cell functions can be impaired by an excess of free radicals (Niess et al. 1999).

During exercise exposure to airborne pathogens is increased due to the higher rate and depth of breathing. An increase in gut permeability may also allow increased entry of gut bacterial endotoxins into the circulation, particularly during prolonged exercise in the heat. Hence, the cause of the increased incidence of infection in athletes is likely to be multifactorial: a variety of stressors (physical, psychological, environmental, nutritional) can depress or suppress immune function and these effects together with increased exposure to pathogens can make the athlete more susceptible to infection.

The relationship between exercise and susceptibility to infection has been modelled in the form of a ' $\mathrm{J}$ ' curve (Nieman, 1994). This model suggests that while engaging in moderate activity may enhance immune function above sedentary levels, excessive amounts of prolonged high-intensity exercise induce detrimental effects on immune function. However, although the literature provides strong evidence in support of the latter point (Nieman, 1994; Pyne, 1994; Pedersen \& Bruunsgaard, 1995; Shephard, 1997; Gleeson \& Bishop, 1999; Mackinnon, 1999), relatively little evidence is available to suggest that there is any clinically significant difference in immune function between sedentary and moderately active persons. Thus, it may be more realistic to 'flatten' out the portion of the curve representing this part of the relationship. Recently Matthews et al. (2002) reported that the regular performance of about $2 \mathrm{~h}$ of moderate exercise per $\mathrm{d}$ was associated with a $29 \%$ reduction in risk of picking up an upper respiratory-tract infection (URTI) compared with a sedentary lifestyle. In contrast, it has been reported that there is a $100-500 \%$ increase in risk of picking up an infection in the weeks following a competitive ultra-endurance running event (Nieman et al. 1990; Peters et al. 1993, 1996).

Acute effects of exercise on immune function. A single, acute session of prolonged strenuous exercise has a temporary depressive effect on immune function and this has been associated with an increased incidence of infection. For example, both Peters \& Bateman (1983) and Nieman et al. (1990) have described a substantially higher (two- to six-fold) frequency of self-reported symptoms of URTI in athletes who completed long-distance foot races compared with control runners who did not compete in the events. An acute bout of physical activity is accompanied by responses that are remarkably similar in many respects to those induced by infection, sepsis or trauma (Northoff et al. 1998; Gleeson \& Bishop, 1999): there is a substantial increase in the number of circulating leucocytes (mainly lymphocytes and neutrophils), the magnitude of which is related to both the intensity and duration of exercise. There are also increases in the plasma concentrations of various substances that are known 
to influence leucocyte functions, including inflammatory and antiinflammatory cytokines such as TNF- $\alpha$, IL-1 $\beta$, IL-6, IL-10, macrophage inflammatory protein-1 and IL-1-receptor antagonist, acute-phase proteins such as CRP and activated complement fragments. The large increases in plasma IL- 6 concentration observed during exercise can be entirely accounted for by release of this cytokine from activated muscle fibres (Steensberg et al. 2000). However, IL-6 production by monocytes (Starkie et al. 2001) and IL-2 and IFN- $\gamma$ (but not IL-4) production by T lymphocytes are inhibited during and for several hours after prolonged exercise (Northoff et al. 1998; Gleeson, 2004). These cytokine changes suggest a shift in the TH1/TH2 balance towards a $\mathrm{TH} 2$ response, which would be expected to decrease host defence against intracellular pathogens.

Hormonal changes also occur in response to exercise, including rises in the plasma concentration of several hormones (e.g. adrenaline, cortisol, growth hormone and prolactin) that are known to have immunomodulatory effects. Phagocytic neutrophils appear to be activated by an acute bout of exercise, but show a diminished responsiveness to stimulation by bacterial lipopolysaccharide (LPS; including both reduced oxidative burst and diminished degranulation responses) after exercise, which can last for many hours (Pyne, 1994; Robson et al. 1999). Acute exercise temporarily increases the number of circulating NK cells but following exercise NK cell numbers decline to less than half of normal levels for a couple of hours; normal resting values are usually restored within 24 h (Shephard \& Shek, 1999). NK cell cytolytic activity (per cell) falls after exercise and if the exercise is both prolonged and vigorous, the decrease in NK cell counts and cytolytic activity may begin during the exercise session (Shephard \& Shek, 1999). During recovery from exercise, lymphokine-activated killer cell numbers and activity also fall below pre-exercise levels. Acute exercise has been shown to diminish the proliferative response of lymphocytes to mitogens (Mackinnon, 1999) and decrease the expression of an early activation marker (CD69) in response to stimulation with mitogen (Ronsen et al. 2001). When the exercise bout is strenuous and very prolonged $(>1.5 \mathrm{~h})$, the number of circulating lymphocytes may be decreased below pre-exercise levels for several hours after exercise and the $\mathrm{T}$ lymphocyte $\mathrm{CD}^{+}: \mathrm{CD}^{+}$ratio is decreased (Berk et al. 1986; Pedersen \& Bruunsgaard, 1995).

APC function is also affected by exercise: exercise-induced reductions in macrophage MHC class II expression and antigenpresenting capacity have been documented (Woods et al. 2000). Both memory $\left(\mathrm{CD} 45 \mathrm{RO}^{+}\right)$and naïve $\left(\mathrm{CD} 45 \mathrm{RA}^{+}\right) \mathrm{T}$ cells increase temporarily during exercise, but the CD45RO:CD45RA ratio tends to increase due to the relatively greater mobilisation of the CD45RO ${ }^{+}$subset (Gannon et al. 2002; Lancaster et al. $2003 a$ ). Following prolonged strenuous exercise the production of Ig by B lymphocytes is inhibited and delayed-type hypersensitivity (DTH) responses (as measured using the CMI Multitest ${ }^{\circledR}$ kit) are diminished (Bruunsgaard et al. 1997). After prolonged exercise, the plasma concentration of glutamine has been reported to fall by about $20 \%$ and may remain depressed for some time. These changes during early recovery from exercise would appear to weaken the potential immune response to pathogens and have been suggested to provide an 'open window' for infection, representing the most vulnerable time period for an athlete in terms of their susceptibility to contracting an infection (Pedersen $\&$ Bruunsgard, 1995). A new and potentially important finding is that following a prolonged bout of strenuous exercise the expression of some TLR on monocytes is decreased (Lancaster et al. 2003c). Furthermore, this is associated with decreased induction of co-stimulatory molecules and cytokines following stimulation with known TLR ligands. These effects may represent a mechanism through which exercise stress impairs immune function and increases susceptibility to infection.

Chronic effects of exercise training on immune function. Chronic exercise (i.e. exercise training) also modifies immune function, with most changes on balance suggesting an overall decrease in immune system function, particularly when training loads are high (Gleeson \& Bishop, 1999). Circulating numbers of leucocytes are generally lower in athletes at rest than in sedentary people, although there is a weak suggestion of a slightly elevated NK cell count and cytolytic action in trained individuals (Shephard \& Shek, 1999). A low blood leucocyte count may arise from the haemodilution (expansion of the plasma volume) associated with training, or may represent increased apoptosis or altered leucocyte kinetics including a diminished release from the bone marrow. Indeed, the large increase in circulating neutrophil numbers that accompanies a bout of prolonged exercise could, over periods of months or years of heavy training, deplete the bone marrow reserve of these important cells. Certainly, the blood population of these cells seems to be less mature than that found in sedentary individuals (Pyne, 1994) and the phagocytic and oxidative burst activities of stimulated neutrophils have been reported to be markedly lower in welltrained cyclists than in age- and weight-matched sedentary controls (Blannin et al. 1996). Levels of secretory Ig such as salivary IgA are lower in athletes engaged in heavy training (Gleeson, 2000), as are $\mathrm{T}$ lymphocyte $\mathrm{CD} 4^{+}: \mathrm{CD}^{+}$ratios and in vitro mitogen-stimulated lymphocyte proliferation responses (Verde et al. 1992; Lancaster et al. 2003b). However, exercise training in healthy young adults does not appear to have an effect on the initiation of a specific antibody response to vaccination or DTH responses as measured with the CMI Multitest ${ }^{\circledR}$ kit (Bruunsgaard et al. 1997). Thus, with chronic periods of heavy training, several aspects of both innate and acquired immunity are depressed.

There are several possible causes of the diminution of immune function associated with heavy training. One mechanism may simply be the cumulative effects of repeated sessions of intense exercise with the consequent elevation of stress hormones, particularly glucocorticoids such as cortisol, causing temporary immunodepression. It is known that both acute glucocorticosteroid administration (Moynihan et al. 1998) and exercise cause a temporary inhibition of IFN- $\gamma$ production by $\mathrm{T}$ lymphocytes and it has been suggested that this may be an important mechanism in exercise-induced depression of immune cell functions (Northoff et al. 1998). When exercise is repeated frequently there may not be sufficient time for the immune system to recover fully. Furthermore, plasma glutamine levels can change substantially after exercise and may become chronically depressed after repeated short periods of prolonged strenuous training (Shephard, 1997). Complement activation also occurs during exercise and a diminution of the serum complement concentration with repeated bouts of exercise, particularly when muscle damage is incurred, could also contribute to decreased innate immunity in athletes (Smith et al. 1990); well-trained individuals have a lower serum complement concentration compared with sedentary controls (Mackinnon, 1999).

In summary, acute short periods of exercise cause a temporary depression of various aspects of immune function (e.g. neutrophil 
respiratory burst, lymphocyte proliferation, monocyte MHC class II expression) that lasts approximately 3 to $24 \mathrm{~h}$ after exercise depending on the intensity and duration of the exercise bout. Periods of intensified training (over-reaching) lasting $7 \mathrm{~d}$ or more result in chronically depressed immune function. Improvements in immune function in athletes as a result of consumption of a nutrient or a specific food could therefore be linked to: (i) an attenuation of the temporary immunodepression following a standardised session of exercise; (ii) an improvement in one or more aspects of immune function in the resting state; or (iii) both (i) and (ii).

\section{Experimental design}

The immune system is affected by a variety of subject-specific and technical factors, which, in an ideal study design, should be strictly controlled in order to reduce the variation in the outcome of immunological measurements (Table 1). In practice, not all factors can be controlled at the same time. In addition, ethical constraints may restrict the use of specific markers in certain populations. Subjects enrolled in human intervention studies should have a defined age range, since immune functions in the elderly can be decreased compared with young subjects, especially when nutrient intakes are low (Lesourd et al. 2002). The sex of the subjects being studied further affects immune functions through endogenous oestrogenic effects (Paavonen, 1994; Bouman et al. 2004). In addition, endogenous hormones during the menstrual cycle in female subjects, and exogenous hormones in the form of contraceptives or of hormone replacement therapy, consistently affect immune functions such as cytokine production (Haus \& Smolensky, 1999), which requires female subjects to be classified as premenopausal (with and without contraceptives) or postmenopausal (with or without hormone replacement therapy). Short-term interventions starting at different phases of the menstrual cycle may also modulate the outcome of the study. BMI is another subject-specific factor with an impact on immune functions (Samartin \& Chandra, 2001; Dandona et al. 2004). A study design accepting a wide range of BMI values may include study subjects with obesity-associated inflammation, which may interfere with the immunomodulating effects of the dietary intervention.

The background diet during the intervention is an important subject-specific factor often neglected in human intervention studies. It determines the general nutritional status of study subjects and thereby modulates their immune status. Including subjects with minor nutrient deficiencies on one hand or subjects using daily multivitamin and mineral supplements on the other may severely influence the immunological impact of the intervention. Further, alcohol and probiotic consumption as well as the level of physical exercise and of smoking all affect immune functions and have to be controlled properly (Watzl \& Watson, 1992; Gill \& Cross, 2002; Petersen \& Pedersen, 2002; Zeidel et al. 2002). The individual phenotype determines in another way the functional status of immune cells. For example, within a population of healthy individuals, NK cell activity can be reproducibly defined as low or high. Therefore, random allocation of individuals with high and low NK cell activity to different treatment groups is highly necessary in studies focusing on this measure of immune function, in order to avoid statistically significant pre-study differences in NK cell activity from occurring. In general the study should contain evidence that parameters of interest have been adequately randomised. Finally, the absence of infections as well as immune system-related diseases in study subjects is a fundamental prerequisite in nutritional immunology studies. Based on the assessment of these subject-specific factors, subjects should be properly matched.

Technical factors are more easily controlled and standardised than are subject-specific factors. First, the appropriate study population and the type of controls have to be identified. In some cases, study subjects could be their own controls, while in other cases a proper selection of controls should be included. Due to the circadian rhythm of immune cell activities (Haus \& Smolensky, 1999), the timing of the blood collection and the fasting period before blood collection have to be standardised. Typically, blood is collected between 07.00 and 10.00 hours in the morning after an overnight fast. Seasonal variations due to environmental factors (differences in the length of the daily light and dark spans, climate, exposure to antigens, diet) may further affect immune functions (Haus \& Smolensky, 1999; Nelson, 2004). The use of depletion or run-in periods prior to a dietary intervention study and appropriate washout periods in cross-over studies are further factors affecting variability. For example, a study investigating the role of different carotenoids on immune functions using a carotenoid depletion period before the beginning of the carotenoid supplementation observed enhanced mitogenic proliferative responsiveness of blood lymphocytes (Kramer \& Burri, 1997), while the same carotenoid supplement had no significant effect on this function in subjects with normal plasma carotenoid profiles at baseline (Cross et al. 1998). The length of the intervention period can also modify the immunological outcome and the

Table 1. Confounding subject-specific and technical factors modulating immune function in human intervention studies

\begin{tabular}{|c|c|}
\hline Subject-specific factors & Technical factors \\
\hline Age & Selection of study population and appropriate controls \\
\hline Sex (hormones, menstrual cycle) & Time of sample collection (circadian rhythm) \\
\hline BMI & Season \\
\hline $\begin{array}{l}\text { Background diet before and during intervention (e.g. probiotic } \\
\text { consumption, micronutrient supplementation) }\end{array}$ & Time since last meal (fasting period) \\
\hline Physical exercise & Use of depletion/washout periods \\
\hline Smoking & Length of intervention period \\
\hline Genetics (low/high responder) & Appropriate selection of immune markers \\
\hline \multicolumn{2}{|l|}{ Presence of infections or other diseases } \\
\hline \multicolumn{2}{|l|}{ Psychological stress } \\
\hline \multicolumn{2}{|l|}{ Sleep deprivation } \\
\hline \multicolumn{2}{|l|}{ Alcohol, drug and medications } \\
\hline Vaccination and infection history & \\
\hline
\end{tabular}


optimal time point to measure dietary effects on the immune system is often difficult to define. As an example, the intake of probiotics temporarily changes the microbial balance in the intestinal tract, which concurrently may initiate an immune response. However, one cannot exclude the possibility that the long-term intake of probiotics over months could result in adaptation and previous changes in immune functions may no longer be measurable. Finally, any dietary intervention should take into account the bioavailability of the relevant nutrient or food component by measuring its concentration or those of its metabolites in blood, urine or faeces and its interactions with other nutrients. The issue of the appropriate selection of immune assays will be discussed later.

\section{Assessment of markers}

Markers to assess immune function in human studies range from the whole organism level to the (sub)cellular, mechanistic level. Clinical endpoints such as mortality and morbidity from (common) infections reflect the overall balance between pathogen exposure and the integrated host defences and as such provide the most relevant indication of the ability to cope with common pathogens. However, natural exposure to pathogens is uncontrolled and unpredictable. This can be overcome experimentally by controlled exposure to vaccines comprising killed or attenuated micro-organisms that trigger in vivo immune responses. Such responses provide valuable information on the ability to respond to a 'model infection'. At the next level, individual aspects of innate and acquired immune function can be assessed ex vivo; i.e. using in vitro assays following in vivo dietary manipulation. Clearly, the clinical relevance of changes in these markers is less clear, but the sensitivity to detect differences may be better and results can provide important mechanistic information that can help in the generation of research hypotheses. Finally, circulating factors (i.e. total Ig, complement proteins, acute-phase proteins, cytokines and cytokine receptors) and cells (leucocytes and lymphocyte subsets) can be measured in blood/serum. These are not functional measures in that they are not indicative of a response to a controlled experimental stimulation of the immune system. Instead they are reflective of spontaneously ongoing responses in vivo. Table 2 provides an overview of the technical characteristics of the immune parameters most commonly used in human nutritional immunology studies. Table 3 provides additional details of the assays frequently used to measure these immune parameters.

A further issue relates to the storage of samples. While fresh cells should always be the first choice, for technical reasons it may sometimes be more practical to work with cryopreserved cells. Studies have shown that assessment of lymphocyte subsets and measurements of NK cell cytotoxicity and lymphocyte proliferation can be performed using cryopreserved cells (Jewett et al. 1976; Fujiwara et al. 1986; Whiteside et al. 1990; Tollerud et al. 1991; Allsopp et al. 1998). However, although most studies did not observe significant differences between fresh and cryopreserved cells, the outcome for some individuals might differ significantly between fresh and cryopreserved cells for unknown reasons. The effect of cryopreservation on lymphocyte proliferation depends on the stimulus used to activate the lymphocytes. There is also a risk that subsets of cells can be selectively lost (Jewett et al. 1976).

\section{In vivo integrated responses}

\section{Immune response to vaccines}

Although some trials have been published in which subjects were deliberately infected with pathogens such as rhinoviruses (Broadbent et al. 1984; Turner \& Cetnarowski, 2000; Turner et al. 2000), Shigella (Tacket et al. 1992) or enterotoxigenic Escherichia coli (Bovee-Oudenhoven et al. 2003), such approaches have ethical constraints. Generally, it is more feasible to use vaccines with killed or attenuated pathogens as model infections. Vaccines trigger in vivo immune responses without eliciting symptoms of disease that would result from inoculation with live pathogens. Specific immune responses to vaccines that are part of a national vaccination schedule can therefore be used as in vivo indicators of the integrated response to those vaccines. Alternatively, one or more selected vaccinations can be integrated into the design of a study. In this case, different types of vaccines can be used to target selective aspects of in vivo immune responses. For instance, polysaccharide vaccines such as Pneumococcus initiate $\mathrm{T}$ cell-independent $\mathrm{B}$ cell responses, whereas first exposure to restricted-use vaccines such as hepatitis B elicits primary $\mathrm{T}$ cell-dependent responses. Secondary or subsequent exposure using vaccines to frequently occurring infections such as influenza or those used in vaccination programmes such as tetanus or diphtheria can be used to indicate recall (memory) responses.

Responses to vaccines are typically assessed as increased concentrations of vaccine-specific antibodies in serum or plasma that are measured by either ELISA or pathogen neutralisation assays. Responsiveness of vaccine-specific B cells can also be assessed as ex vivo secretion of vaccine-specific antibodies following stimulation with vaccine antigen. In addition, cell-mediated responses to certain vaccines have been assessed as a DTH response or as lymphocyte proliferation or cytokine production following ex vivo stimulation of lymphocytes with vaccine antigen (LerouxRoels et al. 1994; Fletcher \& Saliou, 2000; Wiedermann et al. 2000). Combination of different assays provides the opportunity to obtain more detailed information on the response elicited. Moreover, repeated measures can provide information on the kinetics of the dynamic response to a vaccine and can be used not only to assess the initial response to vaccination but also to evaluate the persistence of the antibody titre some months later. The latter is clinically important as, for example, an influenza vaccine given in early autumn would need to maintain high titres for 6 months to give protection throughout the influenza season. For other vaccines such as hepatitis and tetanus toxoid it is desirable to maintain high antibody titres for several years.

As vaccination elicits specific memory, volunteers can be admitted only once to a study that includes a certain vaccination. Also, responses can only be compared between study groups, precluding intra-individual analysis of the impact of intervention and use in trials with a cross-over design. In some cases, it may be necessary to stratify for baseline vaccine-specific immunity as this can vary largely within a population due to prior vaccinations or natural infections. The between-subject variability in response to vaccination is normally also quite high. The period between vaccination and the plateau phase of the response ranges from about 3 weeks (single-dose vaccines) to several months (hepatitis B), indicating that the study period should encompass at least this period. Responses to vaccination are widely used markers of immune function and provide high-quality information on the 
Immunomodulation markers in human nutrition interventions

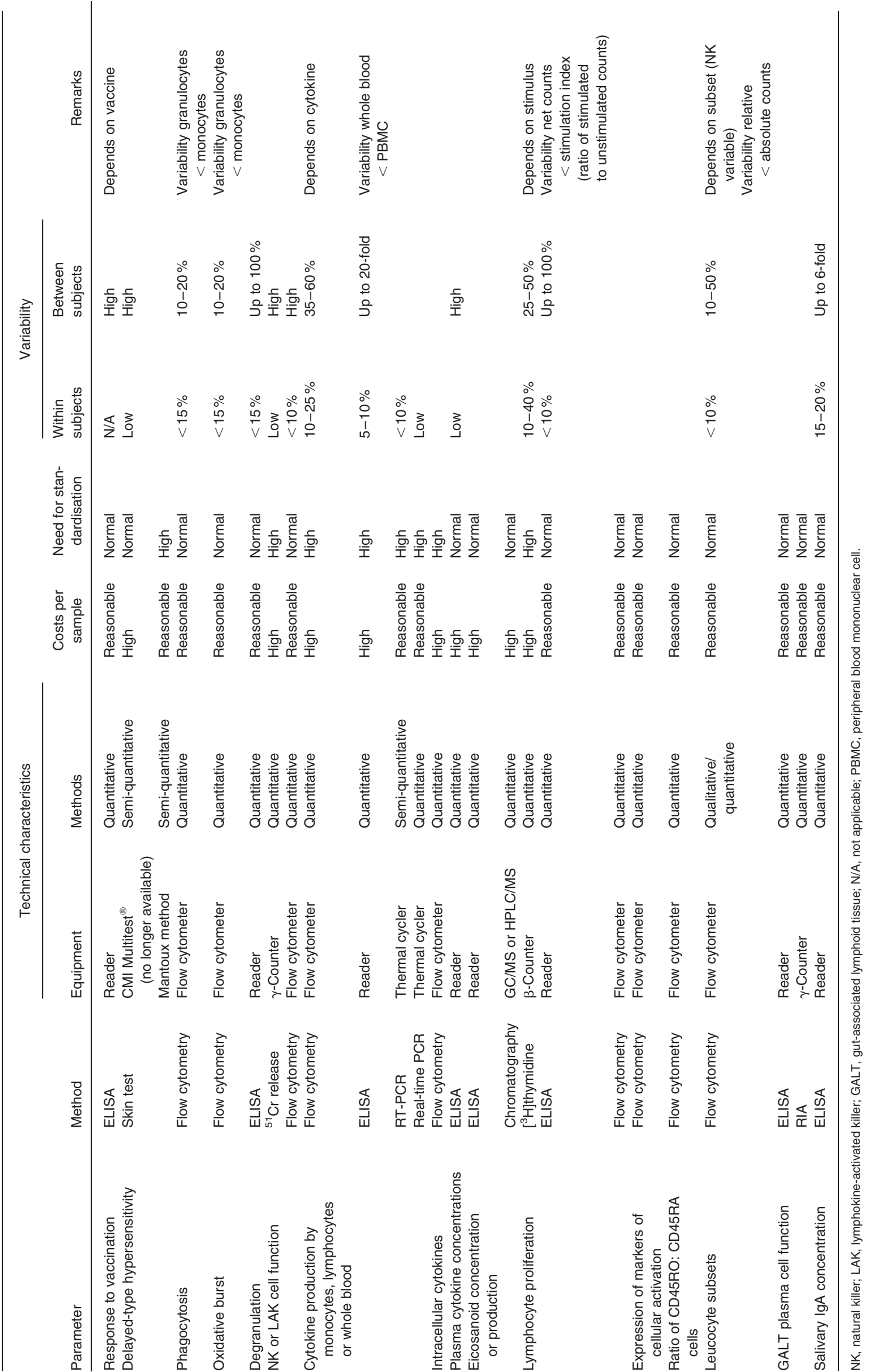




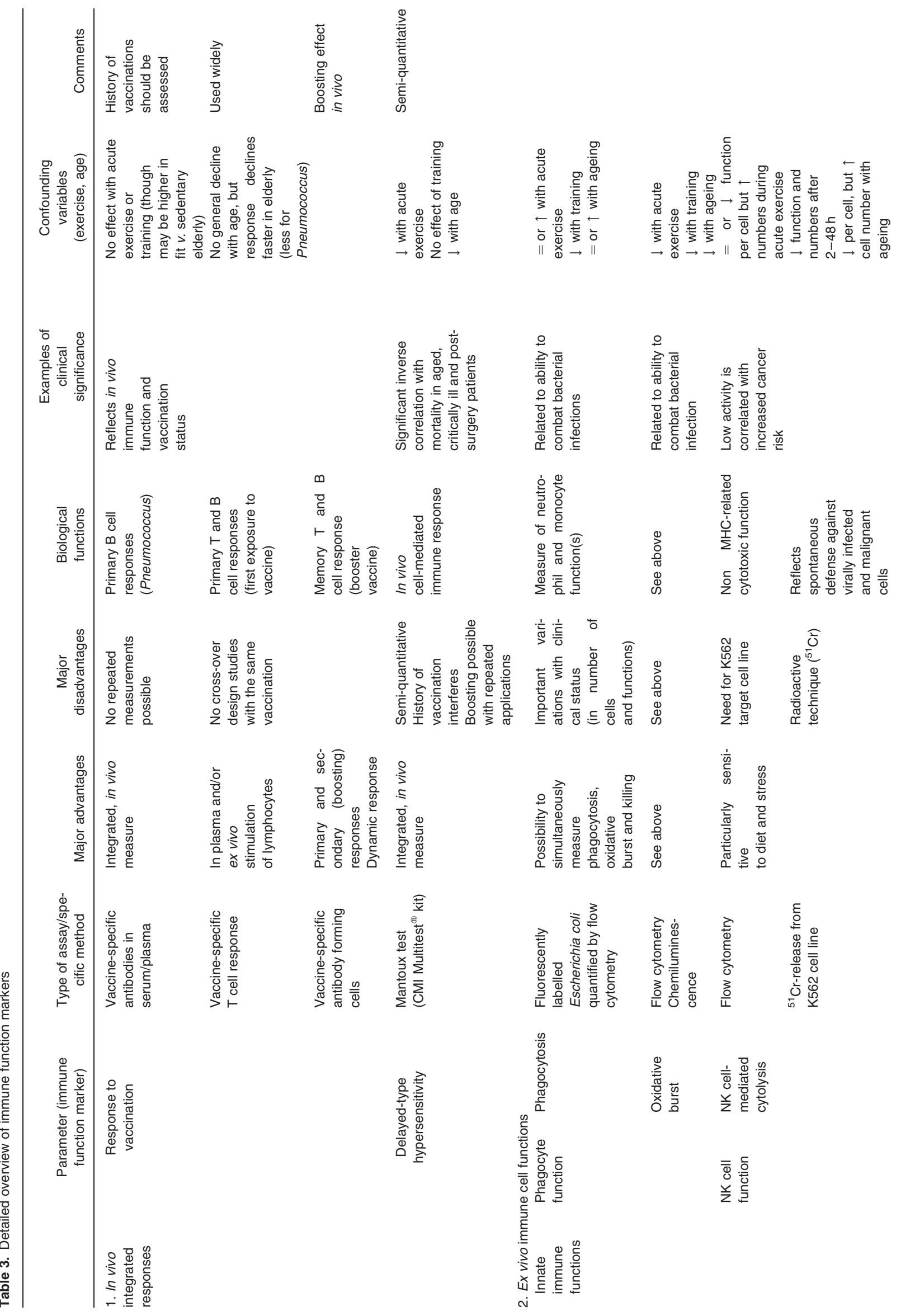


Immunomodulation markers in human nutrition interventions

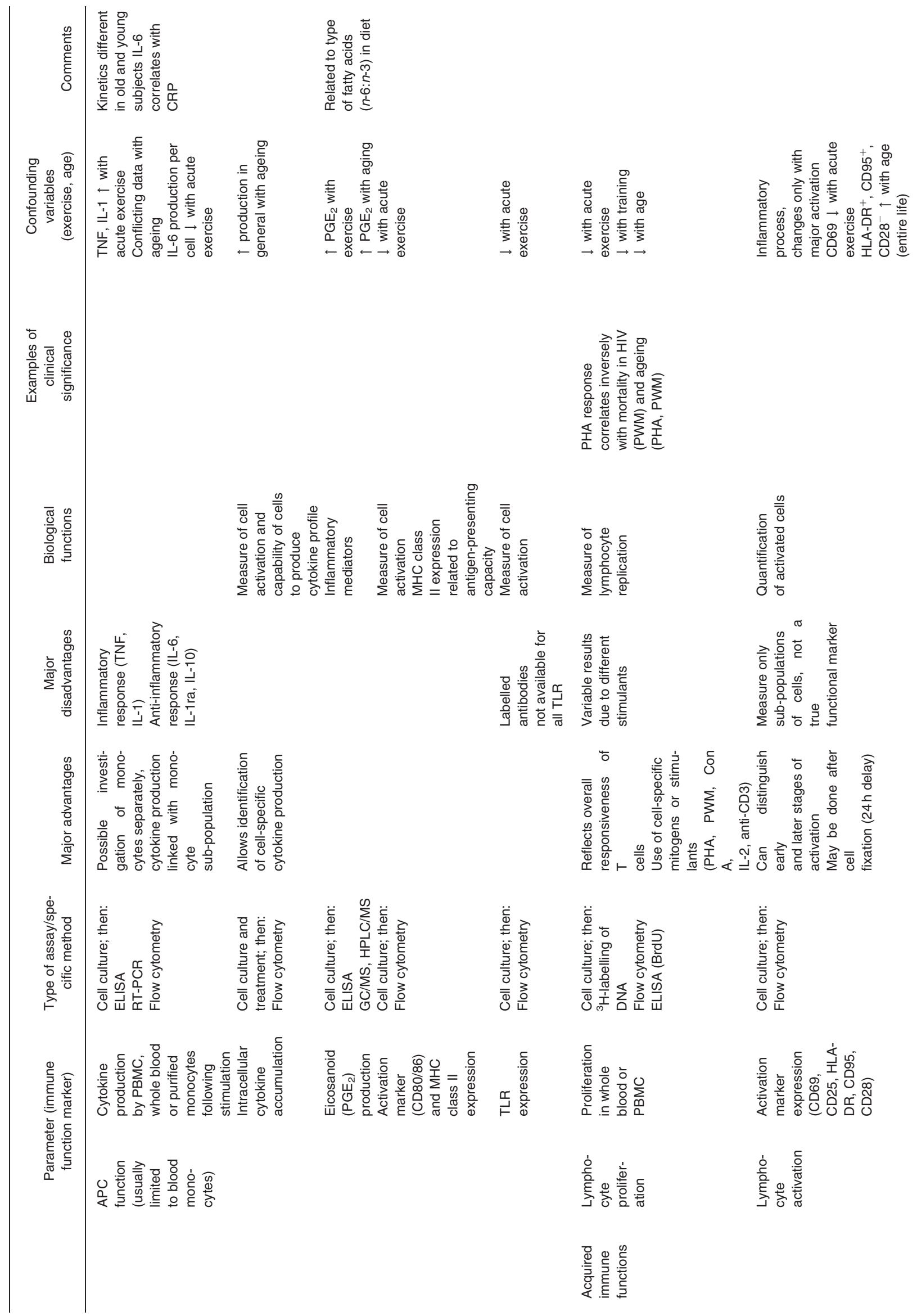


R. Albers et al.

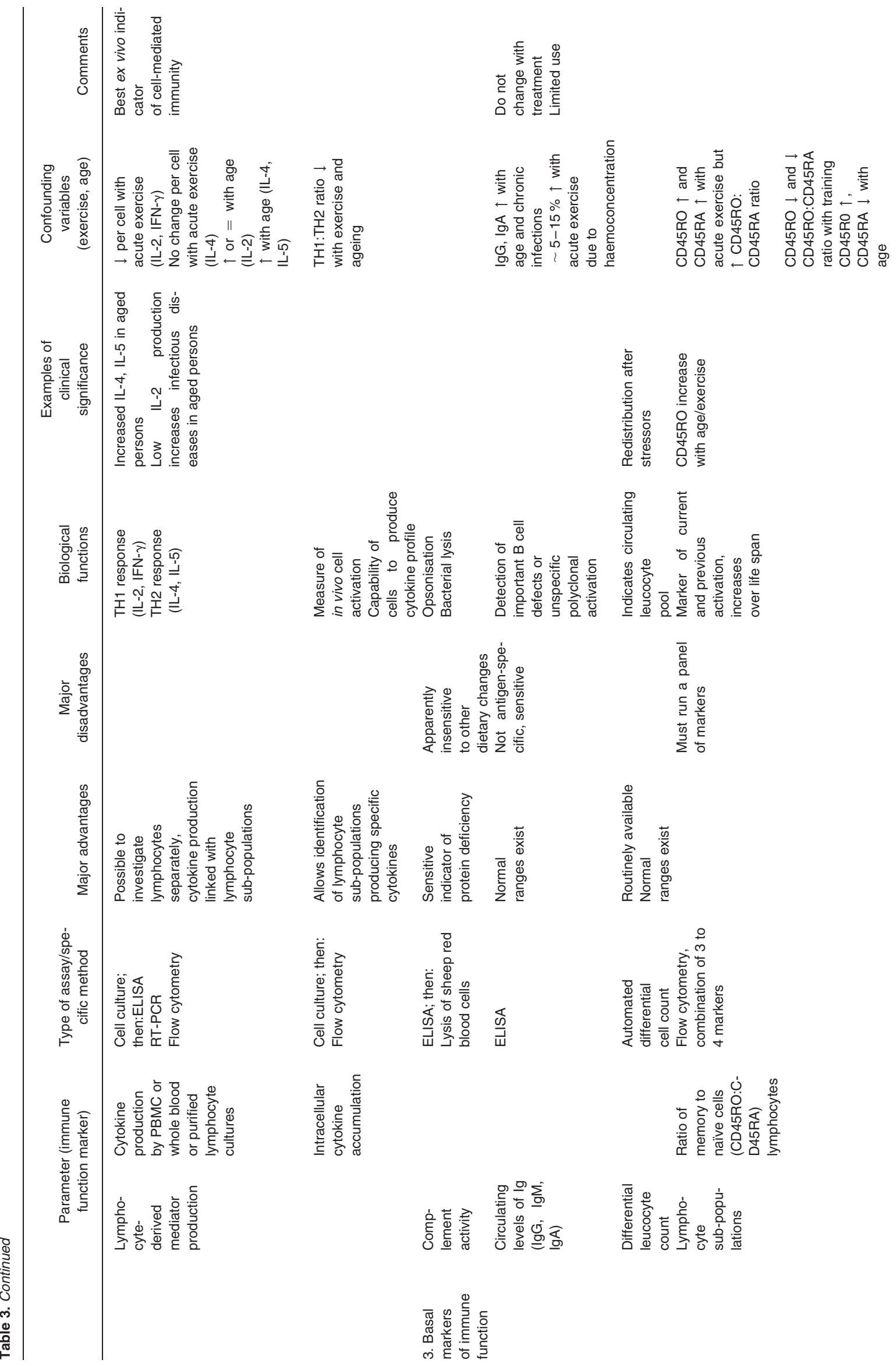


Immunomodulation markers in human nutrition interventions
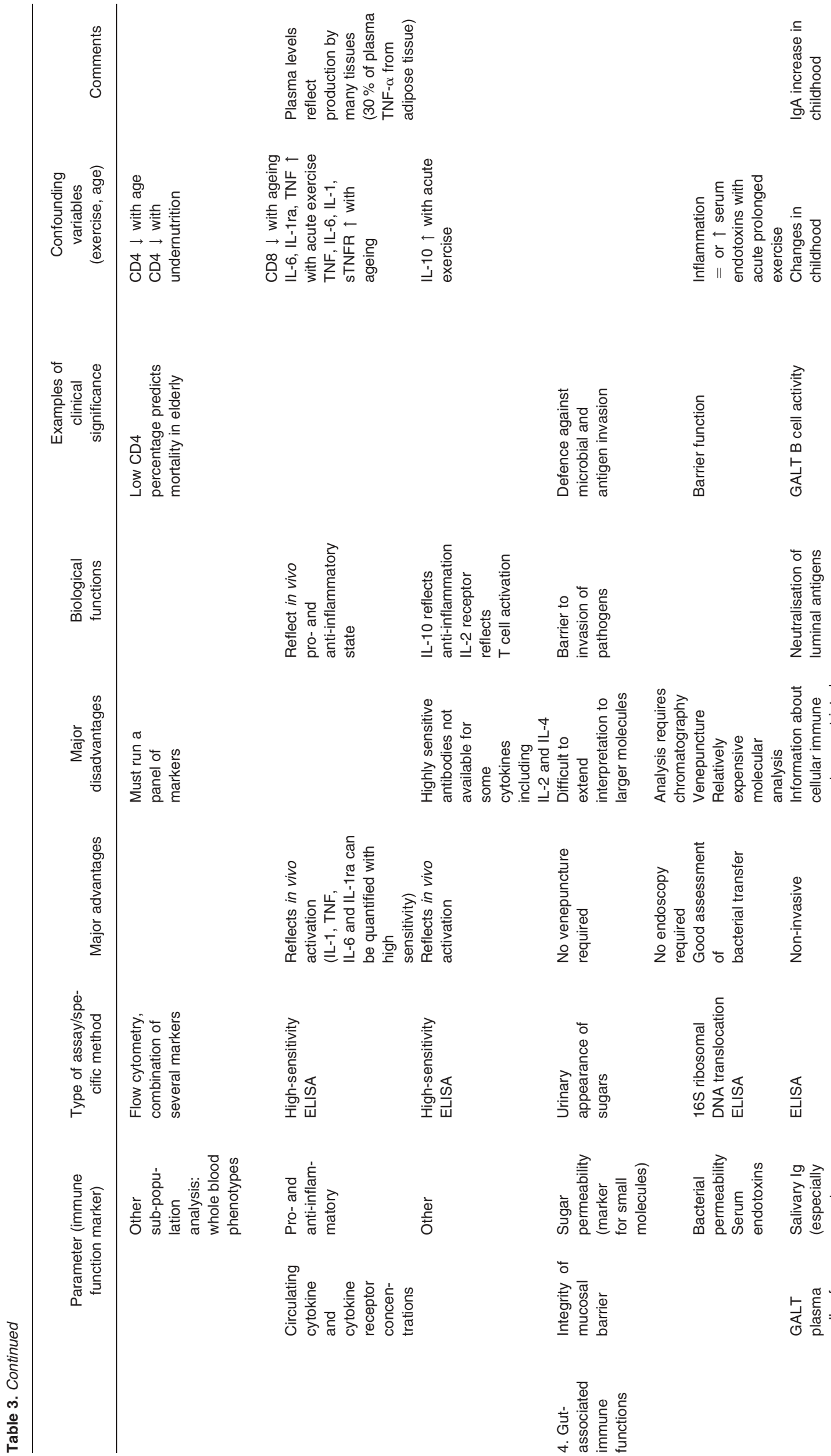

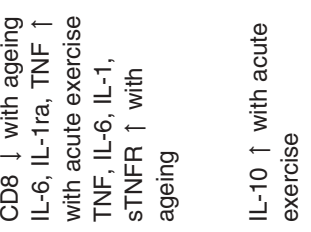
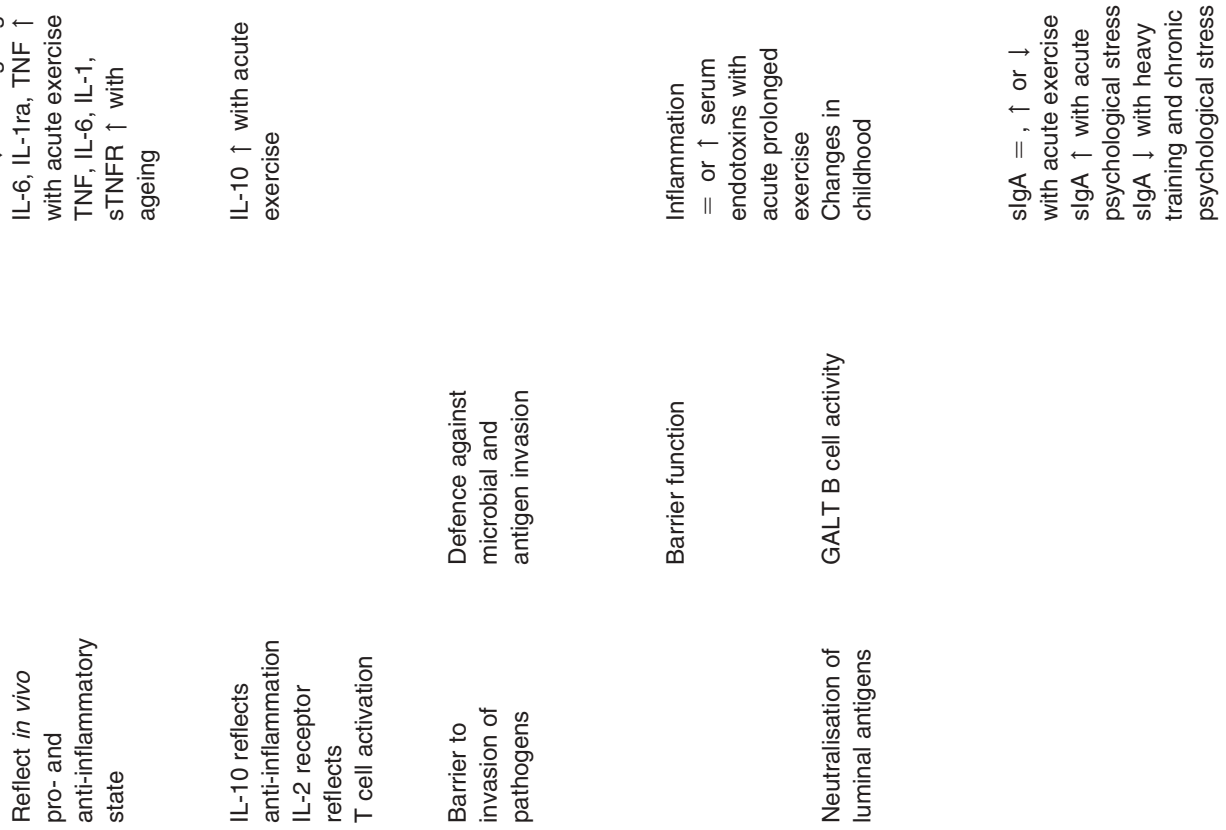

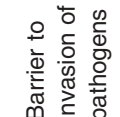

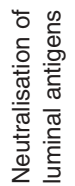
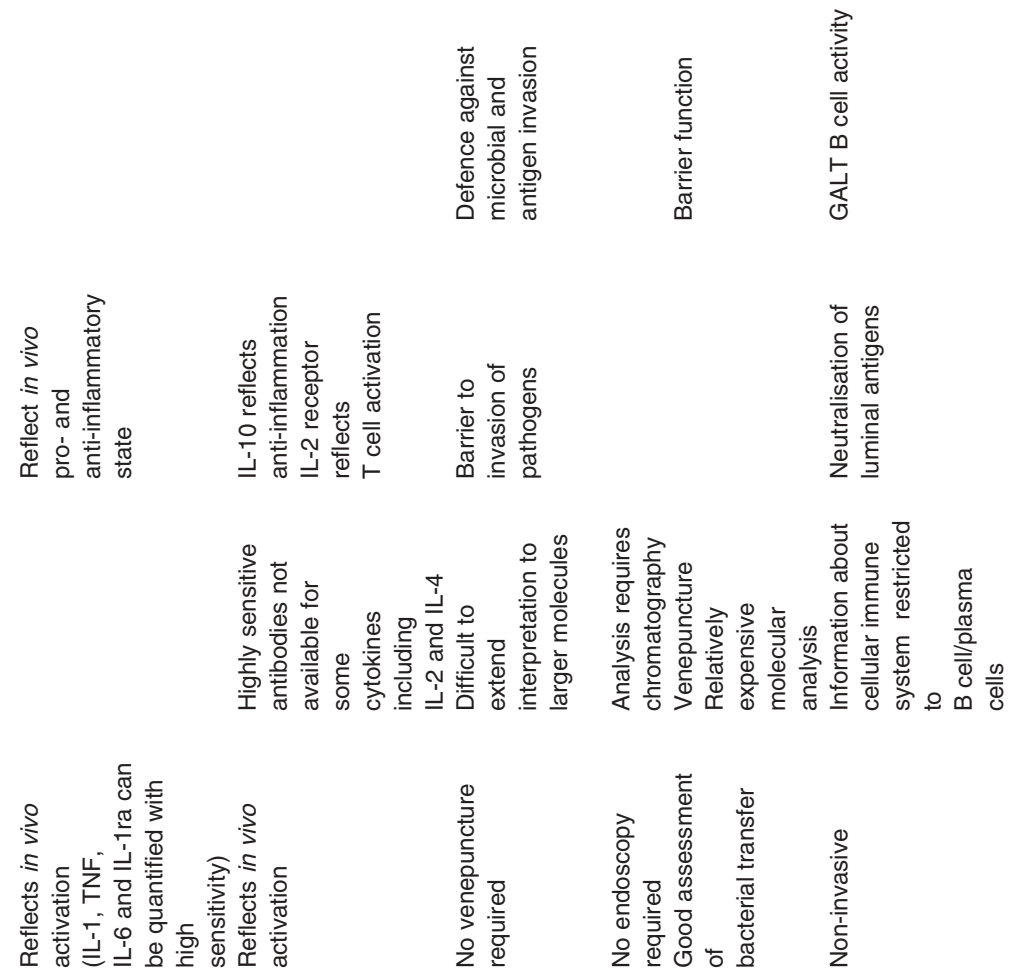

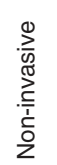

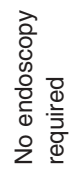

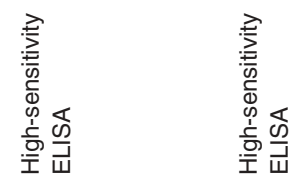

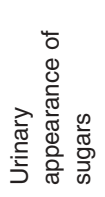

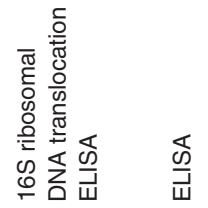

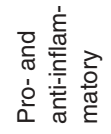

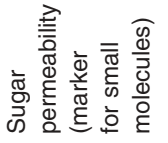

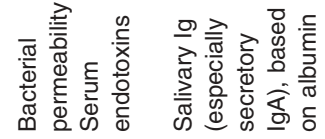

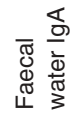

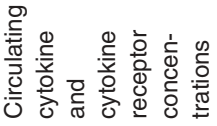

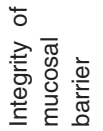

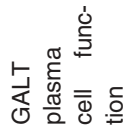

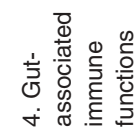


R. Albers et al.

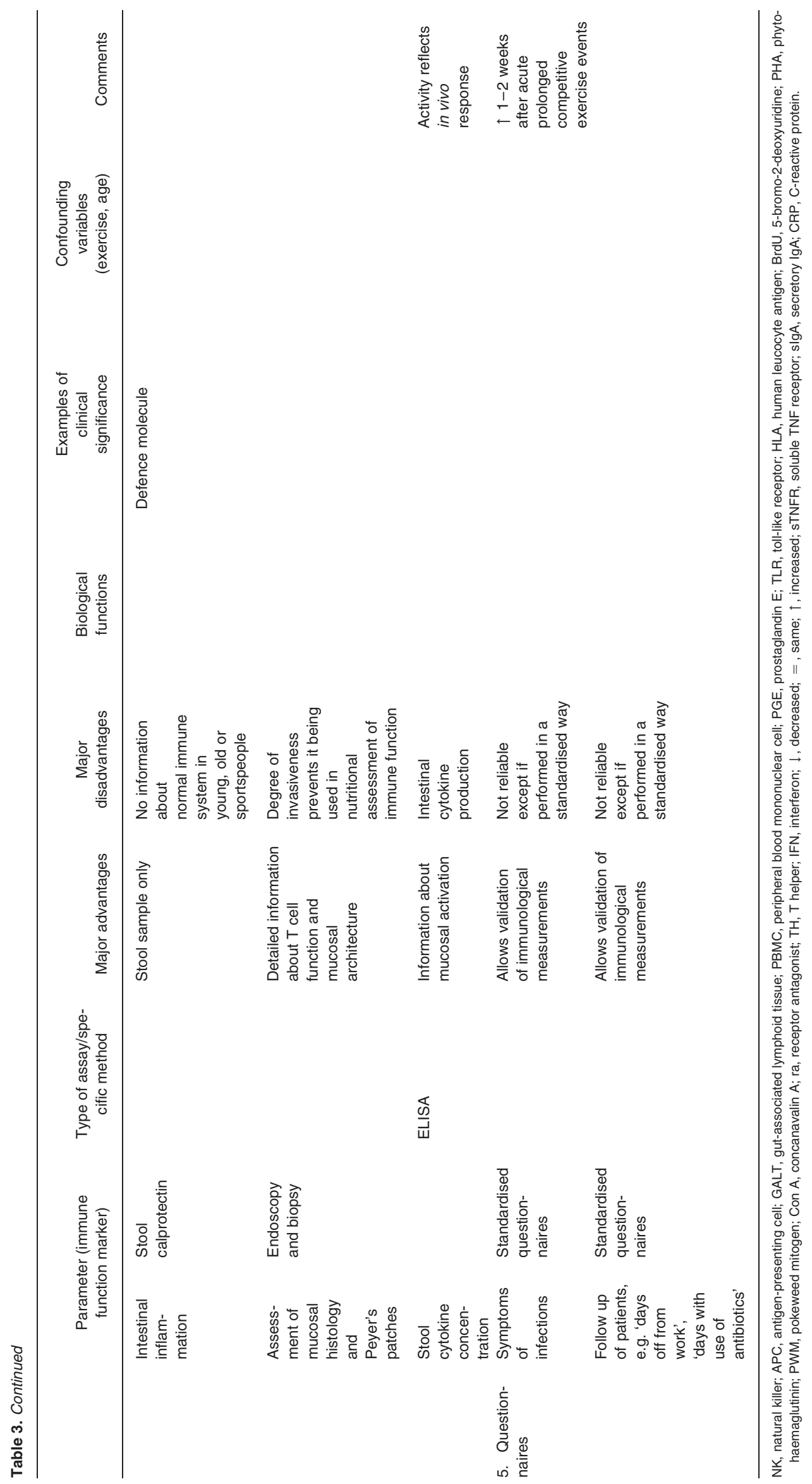


effect of nutrients on protective in vivo immune responsiveness (Meydani et al. 1997; Van Loveren et al. 1999, 2001).

\section{Delayed-type hypersensitivity response}

DTH responses are local cell-mediated responses that are triggered only in sensitised individuals by the intracutaneous administration of antigen. The DTH response can be measured as epidermal induration $24-48 \mathrm{~h}$ after antigen application, which reflects the integrated outcome of a cell-mediated immune response (Ananworanich \& Shearer, 2002). The prototype DTH response is the Mantoux test to diagnose exposure to Microbacterium tuberculosis. The CMI Multitest ${ }^{\circledR}$ was developed to simultaneously administer seven different common antigenic preparations. The dose levels of these preparations were minimised to prevent induction of immunological memory, provided that the test was not used too many times. The test could therefore be used to assess modulation of cellular immune responsiveness by comparing reactions before and after nutritional intervention (Lesourd et al. 1985). As such, the test has been used in numerous nutrition studies but, unfortunately, the CMI Multitest ${ }^{\circledR}$ kit is no longer commercially available. In addition, the individual outcome of the CMI Multitest ${ }^{\circledR}$ was highly variable depending on the subject's vaccination history.

Application of antigenic material by syringe or prick similar to the Mantoux test could be considered as an alternative but since application only yields DTH responses in sensitised subjects, it is important to apply a range of antigens. Sleijffers et al. (2001) measured DTH responses to an uncommon contact sensitiser (diphenylcyclopropenone) after cutaneous sensitisation. Although the deliberate sensitisation may raise some concern, this could potentially be an attractive option as it offers control over both the sensitisation and the elicitation phase of the DTH response. A promising new approach to measure DTH first requires vaccination (e.g. against hepatitis B), which is followed by an intradermal application of the same antigen. However, data from human studies using this approach are not yet available.

DTH responses decline with age (Marrie et al. 1988; Fietta et al. 1994) and are inversely correlated with mortality in surgery patients (Bradley et al. 1981; MacLean, 1988; Christou et al. 1995) and cancer patients (Aziz et al. 1998), with progression to AIDS in persons with HIV infection (Blatt et al. 1993; Gordin et al. 1994), with the risk of URTI (Zaman et al. 1997) and with progression of acute to persistent diarrhoea in Bangladeshi children (Azim et al. 2000). DTH responses that rely on the uncontrolled history of exposure to the antigen have an inherently large inter-individual variation and are therefore not well suited to compare immune responsiveness of individuals or small groups based on a single application. Instead, changes within an individual should be assessed by comparing multiple DTH tests on that individual. It is also essential to standardise the semi-quantitative evaluation of DTH responses. After a strong DTH response, subjects may experience prolonged discoloration/irritation at the site of the response. Despite these limitations, DTH responses are sensitive in vivo indicators of the ability to mount cell-mediated immune responses that have been used successfully in nutrition immunology studies, particularly in subjects with compromised immune function, e.g. due to exposure to uv light (Fuller et al. 1992; Herraiz et al. 1998), and in elderly subjects (Meydani et al. 1990; Bogden et al. 1994; Pallast et al. 1999).

\section{Ex vivo immune functions}

Innate immune system

Phagocyte activity. Phagocytes have an important role in the engulfing and killing of extracellular pathogens and in the removal of antigen-antibody complexes. Neutrophils are the main phagocytic cells in the blood, but monocytes also have some phagocytic activity. Traditionally, phagocytosis was assessed microscopically by counting ingested particles such as erythrocytes, bacteria or latex spheres. The most effective method to measure phagocytosis is based on a flow cytometer, which, today, is standard equipment in many laboratories. With a flow cytometer, the internalisation of fluorescently labelled particles or cells can be measured very efficiently; at the same time this method effectively differentiates between membrane-bound and internalised particles or cells (Lehmann et al. 2000; O'Gorman, 2002). The method provides information on the number of neutrophils and monocytes involved in phagocytosis (percentage of cells that have internalised particles or cells), as well as the level of activity (quantity of internalised particles per active cell expressed as mean or median fluorescence intensity). Flow cytometry also enables the assessment of oxidative burst (the percentage of cells producing reactive oxygen molecules and the mean or median fluorescence intensity per cell) that is triggered by the phagocytosis of bacteria and serves to kill them. Provided that the assay conditions are rigorously standardised (concentration of particles or labelled cells, timing, temperature, selection of stimulus), the assay has a relatively low within- and between-subject variation. A further advantage of the flow cytometric method is that both phagocytosis and oxidative burst can be measured at the same time.

Another aspect of neutrophil function that can be measured in vitro is the degranulation response to bacterial LPS (Robson et al. 1999). Whole blood is incubated with LPS, followed by determination of the amount of elastase released using an ELISA kit specific for polymorphonuclear cell elastase. This method correlates with measures of oxidative burst activity and therefore can be an alternative method for evaluating neutrophil function for laboratories that do not have access to a flow cytometer. These functions demonstrate important variations with clinical status and play an important role in the first defence to bacteria and fungi (Kuritzkes, 2000; Lord et al. 2001; Fidel, 2002).

Natural killer cell activity. NK cells are large, non-T, non-B lymphocytes with an important role in the defence against viruses and other intracellular pathogens. They kill infected and transformed target cells and in the presence of IL-2 contribute to lymphokine-activated killing (lymphokine-activated killer cell activity). To measure NK cell activity, NK-sensitive K562 target cells are briefly co-cultured with NK cells (in peripheral blood mononuclear cells, PBMC) at different ratios. The target cells are frequently pre-labelled with ${ }^{51} \mathrm{Cr}$ or a fluorescent dye (containing non-radioactive $\mathrm{Eu}^{3+}$ ). Subsequent target cell lysis can be measured by the release of radioactivity or fluorescent dye (Nagao et al. 1996), or, alternatively, by the release of cytoplasmic enzymes such as lactate dehydrogenase (Decker \& Lohmann-Matthes, 1988; Konjevic et al. 1997) or by flow cytometric assessment of the uptake of a DNA stain by fluorescently labelled target cells (Provinciali et al. 1992; Chang et al. 1993). The traditional ${ }^{51} \mathrm{Cr}$ method has the disadvantage of using a radioisotope with a short half-life, potential environmental and health hazards, and the spontaneous release of ${ }^{51} \mathrm{Cr}$ from labelled target cells, 
which increases inter-assay variability. However, when highly standardised protocols are used, the results obtained using flow cytometric analysis of target cell DNA staining are identical to those of the ${ }^{51} \mathrm{Cr}$ method ( $r$ 0.91; Chang et al. 1993). All methods require a source of the target cells (K562) for the NK cell lytic activity assay. Target cells should be controlled for mycoplasma on a regular basis to avoid variable sensitivity of the targets to NK cells (Whiteside et al. 1990). NK cell activity can also be measured in cryopreserved NK cells (Fujiwara et al. 1986). However, in some individuals cryopreservation, even under optimal conditions, can decrease NK cell activity (Whiteside et al. 1990). Therefore, the use of fresh NK cells is recommended.

Activity of NK cells appears to be among the immune functions most sensitive to dietary modulation. This may be due to the fact that NK cells are highly dependent on cytokines and are constitutively activated (i.e. they kill unless signalled not to). NK cell activity indicates the spontaneous defence against virus-infected and malignant cells. Low NK cell activity is correlated with increased cancer risk (Imai et al. 2000) and with increased mortality in the elderly (Ogata et al. 2001).

Monocyte-derived mediators. During an infection, various cell types produce peptide (cytokines) and lipid (eicosanoids) mediators with pro- or anti-inflammatory activity. Typically, production of such mediators is assessed in supernatants of PBMC or whole blood cultures after stimulation of the monocytes with Gram-negative bacteria or LPS thereof. These mediators can subsequently be measured in various ways. ELISA are the most frequently used for this purpose. Alternatively, the number of cells producing a particular cytokine can be enumerated using enzyme-linked immunospot assays or flow cytometric analyses of intracellularly labelled cytokines. The latter has the advantage that the phenotype of the producing cells can be determined. Ideally, a cytokine production profile should be determined by examining both pro- (TNF- $\alpha$, IL-1 $\beta$ ) and anti- (IL-1ra, IL-10) inflammatory factors. In comparison with extracellular cytokine detection, intracellular cytokine quantification requires an even more standardised protocol due to the need for additional reagents such as membrane permeabilisers and Golgi apparatus blockers. The most sensitive method to quantify cytokine mRNA levels is reverse transcription in combination with PCR (RT-PCR). To achieve a high reproducibility of quantitative analysis, it is recommended to use a highly standardised protocol with reagents all purchased from the same vendor (Kruse \& Rieckmann, 2002).

For all antibody-based assays (ELISA, flow cytometry), the quality of the antibodies selected for capture and detection of a cytokine is the most crucial factor for specificity and sensitivity of the assay (Remick, 2002). Using isolated monocytes allows the amount of the produced cytokine to be related to a defined cell number. In contrast, the whole blood culture technique measures cytokine production by a known volume of blood. However, this approach does not control for differences in blood cell numbers. To assess cytokine concentrations at different time points (pre- and post-intervention) in longitudinal studies, it is practical to use serially collected frozen aliquots of culture supernatants for cytokine measurements within the same ELISA plate. This will strongly decrease inter-assay variability. The level of cytokine production appears to be characteristic of an individual, resulting in low within-subject variability $(5-10 \%$; Bienvenu et al. 2000). In contrast, marked between-subject variation has been reported with up to sixteen-fold variation in cytokine production by mononuclear cells, which seems likely to be related to polymorphisms in the genes that control cytokine production (Yaqoob et al. 1999). It has to be kept in mind that the presence of soluble cytokine receptors in biological samples can affect the recognition of cytokines by immunoassays.

It has been suggested that production of eicosanoids, of which $\mathrm{PGE}_{2}$ has been measured most frequently, may be related to the type of PUFA (n-6:n-3) in the diet. However, the physiological relevance of this measurement remains to be determined.

Antigen-presenting cell function. Monocytes, macrophages and dendritic cells act as APC and so, in addition to their role as phagocytes, are important in initiating and regulating the adaptive immune response. TLR on macrophages recognise conserved molecular patterns on microbes and initiate intracellular signalling pathways that result in up-regulation of co-stimulatory molecule (CD80/86) and MHC class II protein expression and cytokine production. Expression of TLR (e.g. TLR1, 2, 4 and 9) on $\mathrm{CD}_{1} 4^{+}$monocytes can be quantified by flow cytometry and the extent of APC activation can be assessed by quantifying CD80, CD86, HLA-DR and MHC class II expression or cytokine (e.g. IL-6) production following stimulation with ligands specific for different TLR. The specific pathogen-associated molecular patterns recognised by TLR family members have been well characterised: TLR2 homodimers and TLR2-TLR1 and TLR2TLR6 heterodimers mediate responses to lipoproteins, peptidoglycan, lipoteichoic acid and zymosan; TLR3 to double-stranded RNA; TLR4 to LPS; TLR5 to bacterial flagellin; TLR7 and 8 to imidazoquinolines; TLR9 to bacterial DNA. At present, the clinical significance of these measures of APC function is unclear but it is known that TLR expression and function are influenced by exercise stress and ageing (Renshaw et al. 2002; Lancaster et al. 2003c). In vitro stimulation of monocyte MHC class II protein expression (HLA-DR, -DP, -DQ, etc.) is a useful marker of APC function. Failure of in vivo HLA-DR expression in the monocytes of critically ill patients is a poor prognostic factor for survival. DR is the HLA (human leucocyte antigen) type that has most known disease associations and expression of the other HLA is largely co-regulated. In vitro stimulants include cytokines (e.g. IFN- $\gamma$ ) and bacteria.

\section{Adaptive immune system}

Lymphocyte proliferation. Lymphocytes normally exist as resting cells. Upon stimulation they either enter a pathway of activation-induced cell death, or they become activated and proliferate to expand the number of antigen-specific lymphocytes before these differentiate into effector and memory cells. Activation-induced cell death can be measured using robust, validated techniques such as annexin $\mathrm{V}$ assays that are commercially available and flow cytometry. However, this is not frequently measured in nutrition studies and it is not clear how it relates to resistance to infections. Activation and proliferation of lymphocytes, on the other hand, are often used as indicators of lymphocyte reactivity. Typical stimuli to activate lymphocytes are pokeweed mitogen that stimulates all lymphocytes and the plant lectins phytohaemaglutinin and concanavalin A that stimulate all $\mathrm{T}$ cells. T cells can also be activated with combinations of certain antibodies (i.e. anti-CD3 combined with anti-CD28). The latter resembles the physiological activation more closely and may therefore be preferred (Nisbet-Brown et al. 1987; Meyaard et al. 1995). If possible, it is recommended to combine one or 
more of these polyclonal stimuli with a more specific stimulation, for instance by using the antigen from a vaccine.

For ex vivo stimulation of lymphocytes, usually PBMC are isolated and cultured in medium containing exogenous serum, often fetal bovine serum. However and particularly in nutritional studies, it is important to realise that during isolation and culture the cells' environment, i.e. subset distribution, cell-to-cell contact, exposure to hormones and, most importantly, available nutrients, are changed in such fetal bovine serum-supplemented culture systems. 'Whole blood cultures' provide a pragmatic alternative for the artificial and labour-intensive PBMC cultures. In whole blood assays heparinised blood is cultured undiluted or diluted (1:5 or $1: 10)$ in medium without exogenous serum in the presence of antigen or mitogen (Bloemena et al. 1989; Elsasser-Beile et al. 1991). Pre-assay isolation and counting of cells are not required and cells are cultured in their naturally occurring ratios and in autologous plasma. If desired, production of cytokines per fixed number of particular cells can be calculated after completion of the assay. It is difficult, however, to determine which cells produce which cytokines and effects of nutrients on one cell type can lead to indirect effects on others. Isolated PBMC cultures may therefore be preferred for mechanistic studies, in which case autologous serum or, if that is not possible, pooled human serum or serum-free medium could be considered as an alternative to fetal bovine serum. If fetal bovine serum is used, it is important to use the same batch for all experiments. Proliferation is typically measured as $\left[{ }^{3} \mathrm{H}\right]$ thymidine incorporation into the DNA of proliferating cells, which requires radioisotope handling and access to a scintillation counter. However, alternative methods have been developed assessing incorporation of the thymidine analogue bromodeoxyuridine using ELISA (Martinon et al. 1987) or flow cytometry (Gaines et al. 1996), or fluorescent staining of DNA using propidium iodide. Whereas the sensitivity of the ELISA method is lower than that of $\left[{ }^{3} \mathrm{H}\right]$ thymidine incorporation, its within-subject variability is low (B Watzl, unpublished results). Flow cytometric analysis can be combined with a phenotypic analysis of the proliferating cells and the correlation between this method and $\left[{ }^{3} \mathrm{H}\right]$ thymidine incorporation is very high ( $r$ 0.92; Messele et al. 2000). Proliferation has been measured using cryopreserved human PBMC (Allsopp et al. 1998).

An emerging method is the staining of membranes with a fluorescent dye like carboxyfluorescein diacetate succinimidyl ester that dilutes with each round of division (Lyons, 2000). This method can easily be combined with staining of surface markers to distinguish relevant subsets (i.e. CD4, CD8, CD45RO, CD45RA). Although the method requires further standardisation, it appears to be more robust and less variable than $\left[{ }^{3} \mathrm{H}\right]$ thymidine incorporation and has the advantage that one sample can provide detailed information on the nature of the dividing cells and the number of divisions. Although lymphocyte proliferation has been measured for decades, the methodology is not standardised between laboratories and surprisingly little information is published on variability within individuals and reference ranges. To allow proper interpretation of differences and changes observed, it is therefore important to measure and report the variability within subjects during a study.

Lymphocyte proliferation is one of the most frequently used immune function markers and provides a relatively simple means to determine the ability of lymphocytes to replicate after stimulation. However, results in nutrition studies have been variable, which may, in part, be due to the use of different stimuli that act at different stages of the activation cascade. Lymphocyte proliferation has been shown to correlate inversely with mortality in HIV patients and in elderly subjects (Murasko et al. 1987; Hofmann et al. 1989; Schellekens et al. 1990).

Lymphocyte activation. The activation of lymphocytes can also be assessed by their surface expression of activation markers such as CD69, CD95 and HLA-DR. The use of CD25 as an activation marker has become more complicated since it has been identified as a marker on regulatory T cells. Expression of activation markers is measured by flow cytometry and can easily be combined with further phenotypic analysis of the activated cells, which can be done after a delay of up to $24 \mathrm{~h}$ provided that the cells are fixed after staining. By using antibodies to different activation markers, it is possible to distinguish early (CD69) and late stages (HLA-DR and CD95) of lymphocyte activation. Spontaneous expression of activation markers can be determined on lymphocytes in freshly isolated blood. This is indicative of the in vivo activation of various lymphocyte subsets. Expression can also be assessed after ex vivo stimulation with the same stimuli used to induce lymphocyte proliferation but mitogen-induced expression of CD69 by T cells is less sensitive as an indicator of proliferation than $\left[{ }^{3} \mathrm{H}\right]$ thymidine incorporation (Hutchinson et al. 1999). However, it does appear to be more robust and allows determination of the phenotype of the activated cells.

Lymphocyte-derived mediators. Although it is relevant to know the ability of lymphocytes to become activated and to proliferate, this reveals little about their functional capabilities. For this, functional assays are essential. The function of TH cells is typically assessed as production of cytokines. TH1 and TH2 lymphocytes can be distinguished by the type of cytokines they produce, whereas the level of production indicates the level of activity. TH1 cells typically produce IL- 2 and IFN- $\gamma$, TH 2 cells IL-4, IL-5 and IL-13, and regulatory T cells, IL-10 and TGF- $\beta$. To functionally characterise T cells, lymphocytes are often stimulated in culture and the concentrations of various cytokines in the supernatants are assessed using ELISA. Alternatively, mRNA for cytokines can be assessed using RT-PCR, or the number of lymphocytes that produce a particular cytokine can be enumerated using enzyme-linked immunospot or flow cytometry (Vignali, 2000; Kruse \& Rieckmann, 2002; Remick, 2002). Again, flow cytometric analysis has the advantage that it can be combined with phenotypic analysis of the producing cells. For this, lymphocytes need to be activated in the presence of a protein transport disrupter such as Brefeldin A, which blocks cytokine secretion resulting in intracellular accumulation of cytokines. Ideally, a cluster of cytokines should be assessed to cover TH1, TH2 and regulatory $\mathrm{T}$ cells functions (i.e. IFN- $\gamma$, IL-2, TGF- $\beta$, IL-10, IL-5 and IL-4). As such, production of lymphocyte-derived cytokines following activation provides mechanistic information regarding the immunomodulatory activity of $\mathrm{TH}$ cells.

Activity of cytotoxic $\mathrm{T}$ cells is typically characterised by lysis of antigen-loaded MHC-matched target cells. As human subjects vary widely in their MHC haplotype, this is in practice very difficult to measure and has rarely been used in nutrition studies in man. Production and release of perforin and granzymes assessed by RT-PCR or intracellular staining have been used as surrogate for T cell (and NK cell) cytotoxicity but data on robustness, variability and correlation with relevant clinical endpoints are scarce.

Antibody production. The function of B lymphocytes can be assessed as ex vivo production of antibodies. Traditionally, this 
was done using plaque-forming cell assays, which turned out to be among the markers most predictive of resistance to induced infections in mice using multivariate statistical analyses of immunotoxicological data (Keil et al. 2001). Nowadays, antibody production is typically assessed with an ELISA to determine the concentration of antibodies in the culture supernatant or with an enzyme-linked immunospot assay to enumerate the number of $\mathrm{B}$ cells producing antibodies. With both methods detection can be tailored to total (sub) class of antibodies ( $\operatorname{IgM}, \operatorname{IgG}$, etc.), to antibodies of a particular isotype (IgG1, IgG4, etc.) or to antibodies with particular antigen specificity. These antibodies can be measured without stimulation to assess the spontaneous/in vivo-induced production, or their production can be induced $e x$ vivo by culture in the presence of a polyclonal stimulus like pokeweed mitogen or LPS, or with a specific antigen. The latter appears to be most informative, particularly if used to assess the kinetics of vaccine-specific antibody production following vaccination.

\section{Basal markers of immune functions}

\section{Complement activity}

Complement consists of a series of plasma pro-enzymes synthesised in the liver with a pivotal role in the elimination of pathogens. Complement can be activated by micro-organisms and antibody-antigen complexes. When triggered, this enzyme cascade results in lysis of micro-organisms and enhanced phagocytosis due to opsonisation. Complement factors such as $\mathrm{C} 3$ have been used as indicators of decreased protein synthesis during PEM, but have not generally been found responsive to other dietary changes in non-malnourished subjects. The concentrations of complement factors such as $\mathrm{C} 3$ and $\mathrm{C} 4$ are typically assessed using ELISA and give an indication of complement reserve capacity. The concentrations of activated complement fragments such as $\mathrm{C} 3 \mathrm{a}$ and C5a in vivo can be used as a very good indicator of complement activation and inflammation. This requires the immediate separation of EDTA plasma using EDTA as anticoagulant, but the plasma can be frozen so that assay of activation fragments can be done later. Complement function can be assessed by titrating the lysis of sheep red blood cells. This requires the immediate separation of serum, but this can be frozen so that assay measurements can be done later.

\section{Circulating levels of immunoglobulins}

Serum levels of Ig have been used to assess immune status. Typical ranges in adults for these are: $\operatorname{IgA}, 1.4-4.0 \mathrm{mg} / \mathrm{ml} ; \mathrm{IgD}$, $0-4 \mathrm{mg} / \mathrm{ml}$; IgE, $17-450 \mathrm{ng} / \mathrm{ml}$; IgG, $8-16 \mathrm{mg} / \mathrm{ml}$; IgM, $0 \cdot 5-2 \cdot 0 \mathrm{mg} / \mathrm{ml}$ (Cummings et al. 2004). Conditions with impaired protein synthesis such as PEM result in diminished Ig levels. However, in less extreme cases total levels of Ig are not very responsive to dietary changes and slight variations cannot be interpreted clinically and are of limited use in nutrition studies. However, if the immune system is specifically challenged by a vaccination, detection of antigen-specific antibodies in the serum is the easiest way to assess the adaptive immune response to the antigen. Discrimination of antigen-specific Ig of different isotypes in serum and saliva may provide additional information on the type of immune response elicited (IgG1 and IgG3 indicating TH1-driven responses and $\mathrm{IgG} 4$ and $\mathrm{IgE}$ indicating
TH2-driven responses). During chronic infections, serum levels of $\operatorname{IgG}$ and $\operatorname{IgA}$ tend to increase. Secretory $\operatorname{IgA}$ concentration can be used as an indicator of mucosal immunity (discussed on p. 471).

\section{Circulating acute-phase protein, cytokine and cytokine receptor concentrations}

In the absence of a controlled stimulation such as a vaccination, deviant levels of acute-phase proteins such as CRP, $\alpha$-glycoprotein, albumin and prealbumin in serum or plasma are indicators of ongoing (sub-) clinical infections or other diseases. As such these can be used to help interpret the results of functional assays but by themselves they cannot be extrapolated to immune function or resistance to infections. Using highly sensitive ELISA, various cytokines and soluble variants of cytokine receptors and adhesion molecules involved in leucocyte-endothelial cell interactions can also be measured in serum (or plasma). However, variations have been reported between ELISA kits from different suppliers, partially explaining the wide differences between laboratories. Comparative studies indicate that no difference exists between levels of individual cytokines, apart from IFN- $\gamma$ and IL-10, in plasma and serum (Remick, 2002). Recently, Komatsu et al. (2001) described a highly sensitive method for measuring cytokines directly from serum. With immuno-PCR assay, limits of detection were $0.001 \mathrm{ng} / \mathrm{l}$ for TNF- $\alpha$ compared with $50 \mathrm{ng} / \mathrm{l}$ in an ELISA. This new assay will allow scientists to collect more accurate data on cytokine concentrations in blood. Cytokines, cytokine receptors and soluble adhesion molecules are released during ongoing (inflammatory) immune responses and are affected by certain diseases. Some of these factors can therefore be used as biomarkers for development of diseases that involve early endothelial activation and inflammation. For instance, increased plasma levels of the soluble form of intercellular adhesion molecule- 1 correlate with increased risk for development of CVD. However, the relevance of the circulating forms of cytokines, cytokine receptors and adhesion molecules to immune responsiveness of healthy individuals in the absence of a controlled in vivo stimulus is currently unclear. It is important to realise that the concentrations found in the blood are the net outcome of production in various tissues, including muscle and fat tissue, and degradation by various cells and tissues.

\section{Leucocyte and lymphocyte subsets}

The various cell populations in the blood can be determined by routine haematology, often followed by flow cytometric analysis of lymphocyte subsets. This can provide useful information, for example on redistribution of the leucocyte pool triggered by various stressors including fasting and refeeding (Walrand et al. 2001). However, by themselves, absolute or relative amounts of different leucocyte types are physiologically relevant only in extreme cases such as severe malnutrition and AIDS. On the other hand, haematological and phenotypic analyses do define the cell populations that are used in functional assays and as such provide essential background data for the interpretation of those assays. Standardised systems are nowadays available for the semi-automated multi-parameter quantification of the relative, and after addition of an internal standard, also of the absolute numbers of the main lymphocyte subsets (Table 4). These will 
Table 4. Normal ranges for immune cell numbers in the circulation of human adults

\begin{tabular}{|c|c|c|}
\hline & Number of cells $\left(\times 10^{9}\right)$ per litre blood ${ }^{*}$ & $\%$ of total leucocytes \\
\hline Total leucocytes & $4 \cdot 0-11 \cdot 0$ & 100 \\
\hline Neutrophils & $2 \cdot 0-7 \cdot 5$ & $50-80$ \\
\hline Eosinophils & $0-0.4$ & $0-5$ \\
\hline Basophils & $0-0 \cdot 1$ & $0-2$ \\
\hline Monocytes & $0.2-0.8$ & $2-10$ \\
\hline Lymphocytes & $1.0-3.5$ & $25-50$ \\
\hline T lymphocytes & $0.6-2.5$ & \\
\hline Helper T lymphocytes $\left(\mathrm{CD}^{+} \mathrm{CD}^{+}\right)$ & $0.35-1.5$ & \\
\hline Cytotoxic T lymphocytes $\left(\mathrm{CD} 3^{+} \mathrm{CD}^{+}\right)$ & $0.23-1 \cdot 1$ & \\
\hline B lymphocytes $\left(\right.$ CD19 $\left.{ }^{+}\right)$ & $0.04-0.7$ & \\
\hline Natural killer cells $\left(\mathrm{CD}^{-} \mathrm{CD}^{-} 6^{+}\right)$ & $0 \cdot 2-0 \cdot 7$ & \\
\hline
\end{tabular}

*5th and 95th percentile (MacLennan \& Drayson, 1999).

typically include $\mathrm{TH}$ cells $\left(\mathrm{CD} 4^{+}\right)$, cytotoxic T cells $\left(\mathrm{CD} 8^{+}\right)$, B cells $\left(\mathrm{CD} 19^{+}\right)$and $\mathrm{NK}$ cells $\left(\mathrm{CD} 16^{+} \mathrm{CD} 56^{+}\right)$, but can be extended, for instance, to distinguish naïve $\left(\mathrm{CD} 45 \mathrm{RA}^{+}\right)$and memory cells $\left(\mathrm{CD} 45 \mathrm{RO}^{+}\right)$.

\section{Gut-associated immune functions}

The mucosal immune system is arguably the largest immune component in the body. It defends not only the intestine to invasion by infections, but also plays a similar role in the respiratory system, mouth, eyes and reproductive tract. However, it is that of the intestine that is most widely characterised.

The immune system of the gut divides into the physical barrier of the intestine and the active immune components, which include both innate and adaptive immune responses. The physical barrier is central to the protection of the body to infections. Acid in the stomach, active peristalsis, mucus secretion and the tightly connected monolayer of the epithelium each play a major role in preventing microbial organisms from entering the body.

The cells of the immune system are organised in a complex pattern within the intestine (Fig. 1). Specialised lymphoid tissue with germinal centres, the Peyer's patches, reside below specialised epithelia. This lymphoid-associated epithelium includes M cells, whose structure enables sampling of small particles. Furthermore, other lymphocytes are present both in the lamina propria and associated with the epithelium itself. All cells of the immune system are found in the lamina propria (Fig. 1).

The intestinal epithelium is topologically on the surface of the intestine. However, because of the inversion of the intestine into a tube within the body, its surface is very inaccessible to observers of its function. Currently, testing the immune system of the intestine is achieved only indirectly without very invasive techniques. The latter include endoscopy and biopsy.

Strategies for testing the immune system in the intestine are currently very modest when compared with those used to test systemic immune function. Tests designed to examine the integrity of the intestinal barrier include: (i) those in which markers are given orally (most often a non-metabolisable sugar) and then measured in the urine; (ii) the passage of resident bacteria from the lumen of the intestine into the circulation.

A direct examination of the ability of the intestine to resist infection induced by attenuated pathogens is a promising approach. Bovee-Oudenhoven et al. (2003) administered a live but attenuated enterotoxigenic E. coli strain (strain E1392/752A) to human volunteers in a study of the efficacy of $\mathrm{Ca}$ in enhancing the mucosal immune system and measured clinical response thereafter. Such an approach requires careful attention to the virulence of the infectious agent used and specific ethical considerations.

The most useful marker of the mucosal immune system is $\operatorname{IgA}$. However, measuring elements of the adaptive response relies on the assumption that secretion of Ig, for example, in the mouth reflects that of the rest of the mucosal immune system.

\section{Immunoglobulin A}

$\operatorname{IgA}$ is the predominant $\operatorname{Ig}$ secreted at mucosal surfaces. $\operatorname{IgA}$ is a dimer of $350 \mathrm{kDa}$. The two monomers are joined by a $\mathrm{J}$ chain and protected from proteolysis by another peptide, the secretory component, made by epithelial cells. It is acquired by IgA molecules as they pass through the epithelium on their journey from the plasma cell to the mucosal surface. IgA can immobilise microorganisms or prevent their attachment to mucosal surfaces. Circulating $\operatorname{IgA}$ is mostly monomeric. It is generally believed that most $\operatorname{IgA}$ in the blood is later available for transport to mucosal surfaces.

The production of $\operatorname{IgA}$ at birth is very small and it increases slowly. A 2-year-old child has a serum concentration of $\operatorname{IgA}$ that is half that of adults. IgA levels at mucosal surfaces increase in a similar way.

Salivary IgA can be measured by an ELISA method with a CV of $5-10 \%$. There is some evidence that low levels of salivary IgA are associated with increased incidence of URTI (Isaacs et al. 1984; Mackinnon, 1999; Gleeson, 2000). For the assessment of IgA, unstimulated saliva collections should be made at rest in the post-absorptive or fasted state (Gleeson, 2000) and at specific times during the day and circadian rhythms, because changes in salivary $\operatorname{IgA}$ also occur with acute changes in salivary flow rate. When flow rate increases due to stimulation (e.g. chewing), then salivary $\operatorname{IgA}$ concentration falls. Conversely, if salivary flow rate falls (e.g. in dehydration or heavy exercise), then the salivary $\operatorname{IgA}$ concentration increases. The concentration of $\operatorname{IgA}$ in saliva is decreased during periods of chronic physical or psychological stress.

Finally, various markers for measuring inflammation in the intestine are available for measuring neutrophil components in the stools or markers of protein loss from increased vascular permeability (serum albumin and stool $\alpha_{1}$-antitrypsin). However, the future may bring radical changes in our ability to study the gutassociated immune system. New capsules are available that trans- 


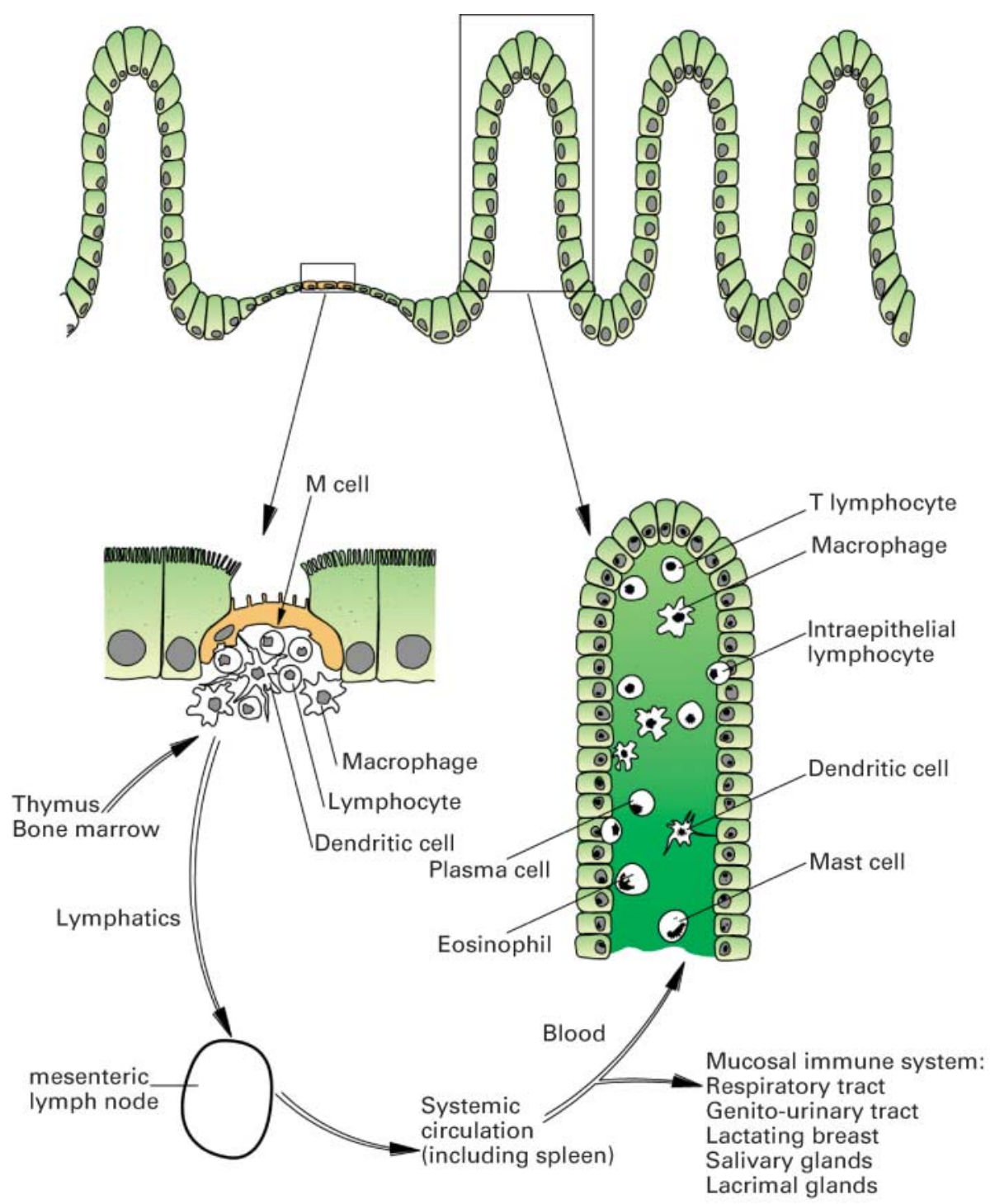

Fig. 1. Diagram of the mucosal immune system. Lymphoid cells arrive from the bone marrow (B cells) or thymus ( $T$ cells) via the systemic circulation and enter the Peyer's patches or isolated lymphoid follicles. Luminal antigen enters these organised lymphoid structures through specialised epithelium containing M cells and is presented to lymphocytes by a variety of antigen-presenting cells. These activated lymphocytes leave the follicle via the mesenteric lymphatics and enter the systemic circulation from where they selectively migrate back to the gastrointestinal tract and to other mucosal effector sites. In the intestine, the two major populations consist of lamina propria lymphocytes and intraepithelial lymphocytes. Lymphocytes in both of these compartments interact with a wide variety of other cell types. Although the small bowel is illustrated here, similar gut-associated lymphoid tissue follicles, migration patterns and effector compartments apply also to the colon. (From Dean \& Elson, 1997.)

mit images of the intestine as they pass down the lumen. Such capsules are currently the subject of technological development. Once these can sample tissue, the way will be open to monitor intestinal immune system in a detailed fashion with techniques that cause a minimum of discomfort.

\section{Questionnaires}

Self-reporting of symptoms of URTI using questionnaires has been used in a number of studies designed to evaluate the effects of chronic psychological stress, exercise or nutritional supplement intervention on infection incidence (e.g. Smith et al. 1989; Nieman et al. 1990; Chandra, 1992; Meydani et al. 1997; Graat et al. 2002; Hamrick et al. 2002). However, this approach leaves such studies open to the criticism that the reporting of symptoms (e.g. sore throat, runny nose, congestion, fever) is subjective and that factors other than infection (e.g. allergies, inhalation of air pollutants) could also cause some of these symptoms. Of course, infection risk not only depends on immune system status but also on the degree of exposure to pathogens and the experience of previous exposure. The average incidence of URTI in adults in developed countries is one or two episodes per individual per year (Matthews et al. 2002) and URTI incidence is higher in the winter months. Thus, such studies require large cohorts of subjects (e.g. fifty or more in placebo and treatment groups) who are followed over a sufficiently long time period (e.g. longer than 6 months) in order to detect potential differences in infection incidence due to a nutritional intervention. 
Questionnaires may also be used to evaluate duration and severity of episodes of symptomatic illness and similar limitations apply to these. Questionnaires can also incorporate general questions such as number of days off work, and use of medications such as antibiotics. Questionnaires should also be used to record any adverse effects of a nutritional intervention. For example, in a placebocontrolled trial that investigated the effects of zinc gluconate supplements in the treatment of acute URTI, nausea and bad taste reactions were reported by $50 \%$ of the subjects taking $\mathrm{Zn}$ (Smith et al. 1989).

In studies using postal questionnaires there may be a response bias. For example, in the study by Nieman et al. (1990), on infection incidence following a marathon race only $47 \%$ of questionnaires were returned, and the respondents may have been mainly those who developed symptoms. Thus, it is preferable that infections are clinically confirmed rather than self-reported. The presence of an infection verified by the isolation of a virus or bacterium from body fluid samples or an increase in the pathogen-specific antibody titre would be the gold standard in this regard. The combined use of good questionnaires and immunological markers in an intervention study can help to better understand the clinical significance of changes in the measured immunological markers. In several studies (e.g. Chandra, 1992; Meydani et al. 1997), the results from questionnaires supported the immunological data. Questionnaires are particularly desirable if in vivo assays of immune function cannot be included in a study.

\section{Emerging techniques and markers}

Our present knowledge of markers of the immune system is inevitably based on our current understanding of immunology and on the techniques available. It is likely that future work will identify new immune markers that are better related to subtle changes in resistance to infections.

\section{Innate immunity}

Recent years have seen a resurgence of interest in the innate immune system (Beutler, 2004). Current knowledge is limited to the identification of components of the immune system that are involved and of their basic interaction with pathogens. Little is known about how alterations in the components of the innate immune system relate to the ability to fight infections.

New information about the recognition of bacterial pathogens by the innate immune system (i.e. pattern recognition receptors) has become an active field of study over the last 5 years since the discovery of TLR (see p. 454). Intracellular molecules (Nod proteins) are also able to recognise other parts of the bacterial cell wall once bacteria have invaded (Girardin \& Philpott, 2004). At present, we have no information as to how the degree of variation in the expression of these receptors may affect resistance to infection. If there is a functional effect of variation, then nutritional modulation of such variation would be important.

Defensins are a series of molecules that can lyse bacteria and other cellular pathogens (Ouellette \& Bevins, 2000). They are produced by a number of different cells including neutrophils, paneth cells and epithelial cells. A series of families of defensins, based on their amino acid structure, exist. Again, future work is needed to establish how expression of the defensins is related to resistance to infection and the possibility that nutrients may alter defensin regulation is an exciting possibility.

\section{Adaptive immunity}

Markers that orchestrate immune function are obvious candidates for studies on resistance to infection. Two sets of $\mathrm{T}$ cells are currently the topic of intensive study and may well lead to useful markers in the future (for reviews see Curotto de Lafaille \& Lafaille, 2002; Walker, 2004). Recent interest has also centred on the question of finding a marker to identify recent thymic emigrants (Ye \& Kirschner, 2002). A variation in the production of T cells from the thymus might be a useful mechanism of marking immune function, if this were proven to be important in the resistance to infection. Lack of a marker to identify recent thymic emigrants is a hurdle to this, but an assay measuring $\mathrm{T}$ cell receptor excision circles has been used as a marker. There is evidence that their concentrations may change during normal ageing and during HIV-1 infection (Touloumi et al. 2004). However, this is still a very new field.

\section{Gut immunity}

Wireless capsule endoscopy. An obvious problem for the assessment of the mucosal immune system is the difficulty in accessing material from the intestine. Endoscopy is a well-validated technique for diagnosing disease and monitoring treatment, but the ethics of performing endoscopy on healthy volunteers is controversial. The use of capsules that pass the gastrointestinal tract (Fritscher-Ravens \& Swain, 2002; Mylonaki et al. 2003; Swain, 2003) may result in new techniques that resolve this problem. Currently, the wireless capsule is a visual relay device that transmits images of the gastrointestinal tract from inside the intestine to a receiver in the subject's jacket. This in turn is used to download a real-time video picture of the surface of the gastrointestinal tract. While such techniques are useful for identifying morphological variations, they are currently limited in their ability to examine the mucosal immune system. Further developments for this will be needed. The first is the ability to control the capsule by the investigator rather than being dependent for its movement on peristalsis. The use of a motor that controls an external caterpillar track around the capsule is one way forward. More problematic is the ability of the capsule to sample material. There are two unresolved areas: the sampling device and the internal storage. In the traditional Crosby capsule used for single duodenal biopsy, these problems were resolved by the rotation of an internal knife that was released by vacuum. It is possible that such adaptations can be utilised in the free-flowing capsule but considerable technical problems remain.

\section{Criteria for the evaluation of immune markers}

Clinical symptoms of infection (e.g. presence, duration and severity of fever or diarrhoea, use of antibiotics) are sometimes used in human trials as an indirect marker of immunocompetence, but such studies typically require a long study period and a large number of subjects. In many situations this is not compatible with the possible size or length of nutrient intervention trials and ex vivo/in vitro immune markers are used instead to assess the effects of interventions. However, these markers have to be 
chosen carefully for the findings to be relevant and of use. A set of criteria has been established here that allows the different markers described above to be evaluated (Table 5). These criteria are 'biological relevance', 'biological sensitivity' and 'feasibility'.

\section{Biological relevance}

Ideally, immune markers should correlate with relevant clinical endpoints and predict resistance to infection and other illnesses associated with dysregulation in immune function. The association between changes in any given immune marker and predisposition to, or presence of, a disease should preferably be known. Thus, markers that are differentially expressed in normal and high-risk or diseased individuals are especially meaningful. Nevertheless, the relationships between ex vivo/in vitro responses and in vivo realities are often quite difficult to establish. In order to understand the biological consequences of changes in immune markers measured ex vivo/in vitro and the relationship of such changes to health, long-term observational studies have to be initiated.

An immune marker could be involved in more than one aspect of the immune response to infection. Experimental, perhaps mechanistic, data that support the biological function of a marker are important to confirm that this marker is specifically involved in the biological process being studied. When a single immune marker is not specific to a particular component of the immune response, then it is essential to use a battery of markers.

\section{Biological sensitivity}

For any immune marker there will be some degree of variation both within and between subjects (Cummings et al. 2004). There are many subject-specific and technical determinants of variability in immune markers and these should be controlled as far as possible (see p. 479). For instance, immune markers are affected by differences or changes in physiological state (e.g. sex, gender, age, menstrual cycle, physical exercise, nervous stress, fed $v$. fasted, alcohol intake, smoking habits) or they may exhibit changes during the day (Liebmann et al. 1998; Haus \& Smolensky, 1999) or with season (Nelson \& Demas, 1996; Mann et al. 2000; Myrianthefs et al. 2003; Nelson, 2004). If these factors are not properly controlled it may be difficult to interpret changes in immune markers following a dietary intervention. In the absence of suitable controls, nutrient-induced changes may not be sufficiently large to allow their identification against the background of the physiological or biological variation.

The sources of variability have to be taken into account when determining the exclusion and inclusion criteria that are used to identify which individuals can participate in an intervention study. The variation between subjects allows the statistical distribution to be determined and will influence decisions about the number of subjects needed in order for the study to be sufficiently powered to identify a statistically significant effect of an intervention. If there are considerable variations in an immune marker, study designs should include measures that are performed both before and during the intervention period within the same subjects to control for this variability. Where possible, placebo-controlled, randomised cross-over designs are preferable, so long as there are no carry-over effects between intervention periods.

\section{Feasibility}

Immune markers should be determined by validated assays that are specific, sensitive, reproducible and robust. Measurement of many of the immune markers described earlier requires immediate processing of blood, which might involve purification and subsequent counting and culture of cells under sterile conditions. Whilst most laboratories will have access to the necessary equipment items (laminar flow cabinet, centrifuges, cell counter, $\mathrm{CO}_{2}$ incubator), measurement of other markers requires the availability of flow cytometry facilities, which may be limited in some settings. Some immune markers (e.g. cytokine production by cultured mononuclear cells) require immediate preparation and culture of cells under standardised conditions, followed by measurement of the marker in the culture supernatant. In such conditions, supernatants are typically stored frozen (preferably at $-80^{\circ} \mathrm{C}$ ) for later batch analysis. The real-time processing of large numbers of blood or cell samples can create logistical difficulties and these need to be considered when planning an intervention study. Thus, for a clinical trial with a large number of enrolled subjects it may be advantageous to exclude markers that are technically or logistically difficult to measure. Cryopreservation of cells for later assessment of function is a possibility for some markers.

\section{Recommendations for the use of immune markers}

The strengths and weaknesses of the different immune markers that are currently available have been evaluated based upon the criteria described previous. Three categories of suitability have been established: high, medium or low (Table 5).

Four highly suitable immune markers have been identified. These are vaccine-specific serum antibody production (see p. 460), the DTH response (see p. 467), vaccine-specific or total secretory IgA in saliva (or other relevant fluids; see p. 471) and the response to attenuated pathogens (see p. 471). These are considered highly suitable because they measure an integrated in vivo response to an immune challenge of some sort. As such, they are each biologically relevant, with an identified association to the clinical endpoint (i.e. a robust host defence against pathogens) and with lower expression in individuals who are more susceptible to infections. The unavailability of the commercial kit for the DTH test will limit the widespread use of this immune marker in the future. However, new approaches to the DTH test are emerging (see earlier) that will most likely allow for the continued measurement of this marker, although this may be confined to fewer laboratories. The response to attenuated pathogens is also an emerging immune marker, but this marker may require special ethical considerations (see p. 459).

A number of ex vivo immune measurements are available, these giving information about the functions of circulating phagocytes, NK cells, APC and lymphocytes (see p. 467). These measurements may be used to provide mechanistic understanding of the effect of an intervention on highly suitable markers. When measurement of a 'preferred' in vivo marker is not possible, the ex vivo markers may be used to assess immune functions. However, it should be noted that these markers are individually considered to be of medium or low suitability (Table 5). This assessment is based largely upon the lack of clear association between a change in an ex vivo immune marker and a change in 
Immunomodulation markers in human nutrition interventions

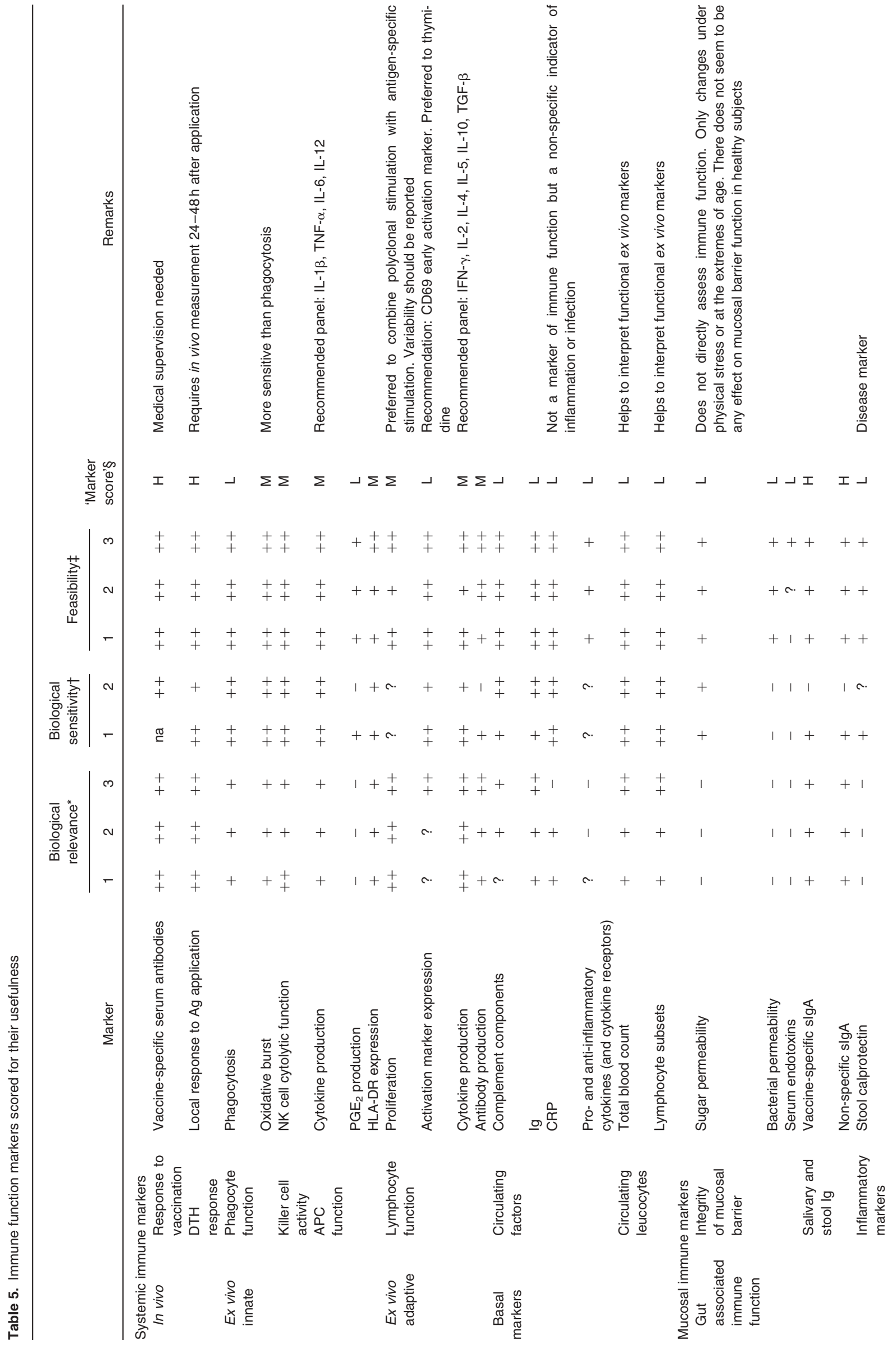


susceptibility to infection. Nevertheless, some of the ex vivo immune markers are sufficiently reliable, sensitive and feasible to support their measurement in human intervention studies. In particular, this applies to measurement of NK cell activity and to phagocyte oxidative burst. Furthermore, a combination of tests representing the function of one type of immune cell or one component of the immune response would be a significant advantage over single marker measurements and is recommended. Indeed, it may be preferable to use several combinations of ex vivo markers. Such combinations might include $\mathrm{T}$ cell proliferation, expression of early and late activation markers on the surface of T cells and production of key TH1-, TH2- and regulatory type $\mathrm{T}$ cytokines (e.g. IFN- $\gamma$, IL-2, IL-4, IL-5, IL-10 and TGF- $\beta$ ) as an overall assessment of $\mathrm{T}$ lymphocyte function, or surface expression of HLA and production of key immunostimulatory cytokines (e.g. IL-1 $\beta$, IL-12) as an overall assessment of APC function. The production of antigen-specific antibodies by cultured lymphocytes taken from individuals sensitised to the antigen (e.g. via vaccination) was considered to be a good measure of B cell function. The use of combinations of immune markers each individually considered to be of medium suitability would greatly increase the confidence in any findings from an intervention study, particularly if consistent effects were seen across the range of related markers. In addition, the combination of markers can provide mechanistic information that might be missed if only single ex vivo markers were measured.

A few of the ex vivo markers are considered to be of low suitability, largely because of the lack of clear association between a change in the marker and a change in susceptibility to infection.

Most of the ex vivo markers referred to earlier and in Table 5 may be evaluated using either whole blood or isolated PBMC, the latter being a mix of lymphocytes and monocytes (approximately 85:15). However, it must be borne in mind that the majority of immune cells are not in the blood circulation. For example, only $2 \%$ of total lymphocytes are circulating at any given time (Westermann \& Pabst, 1990). Furthermore, the activity of blood monocytes might not provide a good indicator of that of tissue macrophages (Ceddia \& Woods, 1999). Isolation of cells from the bloodstream allows for precise control over the number and types of cells being studied. However, isolation removes the cells from the other cell types and blood constituents that they would normally be in contact with and this may alter $e x$ vivo responses compared with those that the cells might undergo in vivo. This places a limit on extrapolation of findings in cell culture to the whole body situation.

All basal immune markers were considered to be of low suitability (Table 5). This is because these markers, which are all measured in the bloodstream, do not typically represent an immune response and so they are not especially informative about how well the immune system will function. For example, in contrast to vaccine-specific antibody responses to vaccination, circulating Ig concentrations are not informative about how the immune system would respond to a challenge. Furthermore, concentrations in the blood compartment may not be representative of concentrations elsewhere. For example, the concentration of IgA in the blood poorly represents the secretion of secretory IgA in the gut (Delacroix et al. 1982). Thus, the measurement of complement components, Ig, cytokines and cytokine receptors in the bloodstream of healthy individuals is not recommended as useful or informative. Exceptions to this might be where specific stresses such as exercise (see p. 457) or eating fat-rich 
meals (Burdge \& Calder, 2005), which are known to elicit responses characterised by increased concentrations of inflammatory cytokines in the bloodstream, are being used.

Measurement of circulating leucocyte subsets was considered to be of low suitability with regard to its relevance as an immune marker that might be sensitive to dietary intervention. Despite this, it is strongly recommended that differential leucocyte counts and identification of mononuclear cell subsets $(\mathrm{T}$, $\mathrm{B}, \mathrm{CD} 4^{+}, \mathrm{CD}^{+}$, NK cells and monocytes) be routinely performed in any intervention study in order to obtain valuable information about the circulating immune cell status of the subjects being studied.

Circulating CRP concentration was also considered to be of low suitability as a marker of immune function. In healthy uninfected individuals CRP concentrations are low but these will increase greatly upon infection. Thus, CRP is not a measure of immune function but of the response of the host to infection. It may be that in some settings CRP concentrations could be used as an outcome indicating the presence of infection. It should also be noted that concentrations below the previously recognised lower threshold of clinical significance $(10 \mathrm{mg} / \mathrm{l})$ are now known to vary among individuals and these low concentrations are positively associated with cardiovascular risk (Albert \& Ridker, 1999).

A number of gut-associated markers were also considered of low suitability. Some of these (sugar and bacterial permeability; serum endotoxin) are not immune markers per se but rather markers of intestinal integrity. Likewise, the concentrations of cytokines and other proteins in faeces or faecal water are indicators of inflammatory activity rather than of immune competence, although these may be targets for anti-inflammatory strategies.

In summary, there is no single immune marker that accurately reflects an individual's resistance to infection and the best measure still is the clinical outcome after infections (incidence, severity and duration of the disease). However, there is a range of in vivo, ex vivo and blood measurements that can be made that reflect, to differing extents, an individual's immune competence. These markers have been evaluated according to several criteria and four in vivo markers were identified as highly suitable for use in human intervention studies. In addition, combinations of several ex vivo immune markers representing the activities of key cells of the immune system were identified as being of medium suitability. Measurements of circulating proteins and of gut integrity were identified as being of low suitability as immune markers. It is recommended that the in vivo markers of systemic or gut-associated immunity be used where possible. These measurements can be supported by the selected, relevant ex vivo markers (NK cell activity, phagocyte oxidative burst, T cell function, B cell function, APC function). This will be of mechanistic value since it will provide an understanding of how an effect on the in vivo marker occurred (or not). In the absence of the in vivo markers, the full combination of ex vivo markers should be used. These recommendations are based upon the current knowledge of the immune system and upon the technologies currently available. It is possible that new immune markers or technologies will become available in the future and these might result in modifications of these recommendations. In order to improve our knowledge in that field, it would be valuable to include a panel of immune markers in the coming clinical trials, as there is a need for data correlating changes in markers with changes in clinical endpoints.

\section{Acknowledgements}

This work was supported by a grant from the Nutrition and Immunity in Man Task Force of ILSI Europe. Industry members of this task force are Campina, Groupe Danone, Nestlé, Numico, Orafti, Seven Seas and Unilever. For further information about ILSI Europe, call +322771·00·14 or email info@ilsieurope.be. The opinions expressed herein are those of the authors and do not necessarily represent the views of ILSI and ILSI Europe.

\section{References}

Albert MA \& Ridker PM (1999) The role of C-reactive protein in cardiovascular disease risk. Curr Cardiol Rep 1, 99-104.

Allsopp CEM, Nicholls SJ \& Langhorne J (1998) A flow cytometric method to assess antigen-specific proliferative responses of different subpopulations of fresh and cryopreserved human peripheral blood mononuclear cells. J Immunol Methods 214, 175-186.

Ananworanich J \& Shearer WT (2002) Delayed-type hypersensitivity skin testing. In Manual of Clinical Laboratory Immunology, 6th ed., pp. 212-219 [NR Rose, B Hamilton and B Detrick, editors]. Washington, DC: ASM Press.

Arreaza EE, Gibbons JJ, Sisking GW \& Weksler ME (1993) Lower antibody response to tetanus toxoid associated with higher auto-anti-idiotype antibody in old compared to young humans. Clin Exp Immunol 92, 169-176.

Azim T, Islam LN, Sarker MS, Ahmad SM, Hamadani JD, Faruque SM \& Salam MA (2000) Immune response of Bangladeshi children with acute diarrhea who subsequently have persistent diarrhea. J Pediatr Gastroenterol Nutr 31, 528-535.

Aziz M, Akhtar S \& Malik A (1998) Evaluation of cell-mediated immunity and circulating immune complexes as prognostic indicators in cancer patients. Cancer Detect Prev 22, 87-99.

Beery TA (2003) Sex differences in infection and sepsis. Crit Care Nurs Clin North Am 15, 55-62.

Berk LS, Ton SA, Nieman DC \& Eby EC (1986) The suppressive effect of stress from acute exhaustive exercise on T-lymphocyte helper/suppressor ratio in athletes and non-athletes. Med Sci Sports Exerc 18, $706-710$.

Beutler B (2004) Innate immunity: an overview. Mol Immunol 40, $845-859$.

Bienvenu J, Monneret G, Fabien N \& Revillard JP (2000) The clinical usefulness of the measurement of cytokines. Clin Chem Lab Med 38, $267-285$.

Blannin AK, Chatwin LJ, Cave R \& Gleeson M (1996) Effects of submaximal cycling and long-term endurance training on neutrophil phagocytic activity in middle-aged men. Br J Sports Med 30, 125-129.

Blatt SP, Hendrix CW, Butzin CA, Freeman TM, Ward WW, Hensley RE, Melcher GP, Donovan DJ \& Boswell RN (1993) Delayed-type hypersensitivity skin testing predicts progression to AIDS in HIV-infected patients. Ann Intern Med 119, 177-184.

Bloemena E, Roos MT, Van Heijst JL, Vossen JM \& Schellekens PT (1989) Whole-blood lymphocyte cultures. J Immunol Methods 122, $161-167$.

Bogden JD, Oleske JM, Lavenhar MA, Munves EM, Kemp FW, Bruening KS, Holding KJ, Denny TN, Guarino MA \& Holland BK (1990) Effects of one year supplementation with zinc and other micronutrients on cellular immunity in the elderly. J Am Coll Nutr 9, 214-225.

Bogden JD, Bendich A, Kemp FW, Bruening KS, Skurnick JH, Denny T, Baker H \& Louria DB (1994) Daily micronutrient supplements enhance delayed-hypersensitivity skin test responses in older people. Am J Clin Nutr 60, 437-447. 
Bouman A, Schipper M, Heineman MJ \& Faas MM (2004) Gender difference in the non-specific and specific immune response in humans. Am J Reprod Immunol 52, 19-26.

Bovee-Oudenhoven IM, Lettink-Wissink ML, Van Doesburg W, Witteman BJ \& Van Der Meer R (2003) Diarrhea caused by enterotoxigenic Escherichia coli infection of humans is inhibited by dietary calcium. Gastroenterology 125, 469-476.

Brabin L (2002) Interactions of the female hormone environment, susceptibility to viral infections, and disease progression. AIDS Patient Care STDS 16, 211-221.

Bradley JA, Ledingham IM \& Hamilton DN (1981) Assessment of host resistance in critically ill surgical patients by the response to recall skin antigens. Intensive Care Med 7, 105-108.

Broadbent DE, Broadbent MH, Phillpotts RJ \& Wallace J (1984) Some further studies on the prediction of experimental colds in volunteers by psychological factors. J Psychosom Res 28, 511-523.

Bruunsgaard H, Hartkopp A, Mohr T, Konradsen H, Heron I, Mordhorst CH \& Pedersen BK (1997) In vivo cell-mediated immunity and vaccination response following prolonged, intense exercise. Med Sci Sports Exerc 29, 1176-1181.

Burdge GC \& Calder PC (2005) Plasma cytokine response during the postprandial period: a potential causal process in vascular disease? $\mathrm{Br}$ J Nutr 93, 3-9.

Cakman I, Rohwer J, Schutz RM, Kirchner H \& Rink L (1996) Dysregulation between TH1 and TH2 cell sub-populations in the elderly. Mech Ageing Dev 87, 197-209.

Calder PC \& Field CJ (2002) Fatty acids, inflammation and immunity. In Nutrition and Immune Function, pp. 57-92 [PC Calder, CJ Field and HS Gill, editors]. Oxford: CABI Publishing.

Calder PC \& Kew S (2002) The immune system: a target for functional foods? Br J Nutr 88, Suppl. 2, S165-S177.

Ceddia MA \& Woods J (1999) Exercise suppresses macrophage antigen presentation. J Appl Physiol 87, 2253-2258.

Chandra RK (1984) Excessive intake of zinc impairs immune responses. JAMA 52, 1443-1446.

Chandra RK (1991) 1990 McCollum Award Lecture: Nutrition and immunity: lessons from the past and new insights into the future. Am J Clin Nutr 53, 1087-1101.

Chandra RK (1992) Effect of vitamin and trace-element supplementation on immune responses and infection in elderly subjects. Lancet $\mathbf{3 4 0}$, $1124-1127$.

Chang L, Gusewitch GA, Chritton DB, Folz JC, Lebeck LK \& NehlsenCannarella SL (1993) Rapid flow cytometric assay for the assessment of natural killer cell activity. J Immunol Methods 166, 45-54.

Christou NV, Meakins JL, Gordon J, Yee J, Hassan-Zahraee M, Nohr CW, Shizgal HM \& MacLean LD (1995) The delayed hypersensitivity response and host resistance in surgical patients: 20 years later. Ann Surg 222, 534-546.

Cohen S, Tyrrell DA \& Smith AP (1991) Psychological stress and susceptibility to the common cold. $N$ Eng J Med 325, 606-612.

Cossarizza A, Ortolani C, Paganelli R, et al. (1992) Age-related imbalance of virgin $\left(\mathrm{CD} 45 \mathrm{RA}^{+}\right)$and memory $\left(\mathrm{CD} 45 \mathrm{RO}^{+}\right)$cells between $\mathrm{CD} 4^{+}$ and $\mathrm{CD}^{+} \mathrm{T}$ lymphocytes in humans: study from newborns to centenarians. J Immunol Res 4, 117-126.

Cross NA, Shetty G, Nordstrom JW, Davis CA \& Kramer TR (1998) Effects of mixed-carotenoid supplementation on plasma carotene concentrations and $\mathrm{T}$ lymphocyte immunocompetence in elderly black women. FASEB J 12, A857 Abstr.

Cummings JH, Antoine J-M, Aspiroz F, et al. (2004) PASSCLAIM - Gut health and immunity. Eur J Nutr 43, Suppl. 2, 118-173.

Curotto de Lafaille MA \& Lafaille JJ (2002) CD4 (+) regulatory T cells in autoimmunity and allergy. Curr Opin Immunol 14, 771-778.

Dandona P, Aljada A \& Bandyopadhyay A (2004) Inflammation: the link between insulin resistance, obesity and diabetes. Trends Immunol 25, $4-7$.

Decker T \& Lohmann-Matthes ML (1988) A quick and simple method for the quantitation of lactate dehydrogenase release in measurements of cellular cytotoxicity and tumor necrosis factor (TNF) activity. J Immunol Methods 115, 61-69.

Dean PA \& Elson CD (1997) Immunology. In Surgery of the Colon and Rectum, p. 57 [RJ Nicholls and RR Dozois, editors]. New York: Churchill Livingstone.

Delacroix DL, Dive C, Rambaud JC \& Vaerman JP (1982) IgA subclasses in various secretions and in serum. Immunology 47, 383-385.

Elsasser-Beile U, von Kleist S \& Gallati H (1991) Evaluation of a test system for measuring cytokine production in human whole blood cell cultures. J Immunol Methods 139, 191-195.

Faas M, Bouman A, Moesa H, Heineman MJ \& de Leij L (2000) Schuiling $\mathrm{G}$ The immune response during the luteal phase of the ovarian cycle: a TH2-type response. Fertil Steril 74, 1008-1013.

Fidel PL Jr (2002) Immunity to Candida. Oral Dis 8, Suppl. 2, 69-75.

Fietta A, Merlini C, Dos SC, Rovida S \& Grassi C (1994) Influence of aging on some specific and nonspecific mechanisms of the host defense system in 146 healthy subjects. Gerontology 40, 237-245.

Fletcher MA \& Saliou P (2000) Vaccines and infectious disease. EXS 89, 69-88.

Fritscher-Ravens A \& Swain CP (2002) The wireless capsule: new light in the darkness. Dig Dis 20, Suppl. 2, 127-133.

Fujiwara S, Akiyama M, Yamakido M, Seyama T, Kobuke K, Hakoda M, Kyoizumi S \& Jones SL (1986) Cryopreservation of human lymphocytes for assessment of lymphocyte subsets and natural killer cytotoxicity. J Immunol Methods 90, 265-273.

Fuller CJ, Faulkner H, Bendich A, Parker RS \& Roe DA (1992) Effect of $\beta$-carotene supplementation on photosuppression of delayed-type hypersensitivity in normal young men. Am J Clin Nutr 56, 684-690.

Gaines H, Andersson L \& Biberfeld G (1996) A new method for measuring lymphoproliferation at the single-cell level in whole blood cultures by flow cytometry. J Immunol Methods 195, 63-72.

Gannon GA, Rhind S, Shek PN \& Shephard RJ (2002) Naïve and memory $\mathrm{T}$ cell subsets are differentially mobilized during physical stress. Int $J$ Sports Med 23, 223-229.

Gardner EM \& Murasko DM (2002) Age-related changes in type 1 and type 2 cytokine production in humans. Biogerontology 3, 271-290.

Gill HS \& Cross ML (2002) Probiotics and immune function. In: Nutrition and Immune Function, pp. 251-272 [PC Calder, CJ Fields and HS Gill, editors]. Oxford: CABI Publishing.

Girardin SE \& Philpott DJ (2004) Mini-review: the role of peptidoglycan recognition in innate immunity. Eur J Immmunol 34, 1777-1782.

Gleeson M (2000) Mucosal immune responses and risk of respiratory illness in elite athletes. Exerc Immunol Rev 6, 5-42.

Gleeson M (2004) Immune function and exercise. Eur J Sport Sci 4, $52-61$.

Gleeson M \& Bishop NC (1999) Immunology. In Basic and Applied Sciences for Sports Medicine, pp. 199-236 [RJ Maughan, editor]. Oxford: Butterworth Heinemann.

Gordin FM, Hartigan PM, Klimas NG, Zolla-Pazner SB, Simberkoff MS \& Hamilton JD (1994) Delayed-type hypersensitivity skin tests are an independent predictor of human immunodeficiency virus disease progression. Department of Veterans Affairs Cooperative Study Group. J Infect Dis 169, 893-897.

Graat JM, Schouten EG \& Kok FJ (2002) Effect of daily vitamin E and multivitamin-mineral supplementation on acute respiratory tract infections in elderly persons: a randomized control trial. JAMA $\mathbf{2 8 8}$, 715-721.

Hamrick N, Cohen S \& Rodriguez MS (2002) Being popular can be healthy or unhealthy: stress, social network diversity, and incidence of upper respiratory tract infection. Health Psychol 21, 294-298.

Haus E \& Smolensky MH (1999) Biologic rhythms in the immune system. Chronobiol Int 16, 581-622.

Hayek GM, Mura C, Wu D, Beharka AA, Han SN, Paulson E, Hwang D \& Meydani SN (1997) Enhanced expression of inducible cyclooxygenase with age in murine macrophages. J Immunol 159, 1445-1451. 
Heath GW, Ford ES, Craven TE, Macera CA, Jackson KL \& Pate RR (1991) Exercise and the incidence of upper respiratory tract infections. Med Sci Sports Exerc 23, 152-157.

Herraiz LA, Hsieh WC, Parker RS, Swanson JE, Bendich A \& Roe DA (1998) Effect of UV exposure and $\beta$-carotene supplementation on delayed-type hypersensitivity response in healthy older men. $J \mathrm{Am}$ Coll Nutr 17, 617-624.

Hofmann B, Bygbjerg I, Dickmeiss E, Faber V, Frederiksen B, Gaub J, Gerstoft J, Jakobsen BK, Jakobsen KD \& Lindhardt BO (1989) Prognostic value of immunologic abnormalities and HIV antigenemia in asymptomatic HIV-infected individuals: proposal of immunologic staging. Scand J Infect Dis 21, 633-643.

Hutchinson P, Divola LA \& Holdsworth SR (1999) Mitogen-induced Tcell CD69 expression is a less sensitive measure of T-cell function than $\left[{ }^{3} \mathrm{H}\right]$-thymidine uptake. Cytometry 38, 244-249.

Imai K, Matsuyama S, Miyake S, Suga K \& Nakachi K (2000) Natural cytotoxic activity of peripheral-blood lymphocytes and cancer incidence: an 11-year follow-up study of a general population. Lancet 356, 1795-1799.

Isaacs D, Webster ADB \& Valman HB (1984) Immunoglobulin levels and function in preschool children with recurrent respiratory infections. Clin Exp Immunol 58, 335-340.

Janeway CA, Travers P, Walport M \& Shlomchik M (2005) Immunobiology, 6th ed. London: Garland Publishing.

Jemmott JB, Borysenko JZ, Borysenko M, McClelland DC, Chapman R, Meyer D \& Benson H (1983) Academic stress, power motivation, and decrease in secretion rate of salivary secretory immunoglobulin A. Lancet 1, 1400-1402.

Jewett MA, Gupta S, Hansen JA, Cunningham-Rundles S, Siegal FP, Good RA \& Dupont B (1976) The use of cryopreserved lymphocytes for longitudinal studies of immune function and enumeration of subpopulations. Clin Exp Immunol 25, 449-454.

Keil D, Luebke RW \& Pruett SB (2001) Quantifying the relationship between multiple immunological parameters and host resistance: probing the limits of reductionism. J Immunol 167, 4543-4552.

Komatsu M, Kobayashi D, Saito K, Furuya D, Yagihashi A, Araake H, Tsuji N, Sakamaki S, Niitsu Y \& Watanabe N (2001) Tumor necrosis factor-a in serum of patients with inflammatory bowel disease as measured by a highly sensitive immuno-PCR. Clin Chem 47, 1297-1301.

Konjevic G, Jurisic V \& Spuzic I (1997) Corrections to the original lactate dehydrogenase (LDH) release assay for the evaluation of NK cell cytotoxicity. J Immunol Methods 200, 199-201.

Kramer TR \& Burri BJ (1997) Modulated mitogenic proliferative responsiveness of lymphocytes in whole-blood cultures after a low-carotene diet and mixed-carotenoid supplementation in women. Am J Clin Nutr 65, 871-875.

Kruse N \& Rieckmann P (2002) Molecular analysis of cytokines and cytokine receptors. In Manual of Clinical Laboratory Immunology, 6th ed., pp. 347-356 [NR Rose, B Hamilton and B Detrick, editors]. Washington, DC: ASM Press.

Kuritzkes DR (2000) Neutropenia, neutrophil dysfunction, and bacterial infection in patients with human immunodeficiency virus disease: the role of granulocyte colony-stimulating factor. Clin Infect Dis 30, 256-260.

Lancaster GL, Halson SL, Khan Q, Drysdale P, Jeukendrup AE, Drayson MT \& Gleeson M (2003a) Effect of acute exhaustive exercise and a 6-day period of intensified training on immune function in cyclists. J Physiol 548, O96.

Lancaster GL, Halson SL, Khan Q, Drysdale P, Jeukendrup AE, Drayson MT \& Gleeson M (2003b) Effect of exhaustive exercise and intensified training on human T-lymphocyte CD45RO expression. J Physiol 548, O97.

Lancaster GL, Khan Q, Drysdale P, Jeukendrup AE, Drayson MT \& Gleeson $\mathrm{M}(2003 c)$ The effect of exercise on the expression and function of human monocyte toll-like receptors. J Physiol 555, C112.

Lehmann AK, Sornes S \& Halstensen A (2000) Phagocytosis: measurement by flow cytometry. J Immunol Methods 243, 229-242.
Leroux-Roels G, Van Hecke E, Michielsen W, Voet P, Hauser P \& Petre J (1994) Correlation between in vivo humoral and in vitro cellular immune responses following immunization with hepatitis B surface antigen (HBsAg) vaccines. Vaccine 12, 812-818.

Lesourd B (1999) Immune responses during diseases and recovery in the elderly. Proc Nutr Soc 58, 1-14.

Lesourd B (2000) Undernutrition: a factor of accelerated ageing in healthy and diseased aged persons. In Handbook of Nutrition in the Aged Persons, pp. 145-158 [RR Watson, editor]. New York: CRC Press.

Lesourd BM, Wang A \& Moulias R (1985) Serial delayed cutaneous hypersensitivity skin testing with multiple recall antigens in healthy volunteers: booster effect study. Ann Allergy 55, 729-735.

Lesourd BM, Mazari L \& Ferry M (1998) The role of nutrition in immunity in the aged. Nutr Rev 56, S113-S125.

Lesourd B, Raynaud-Simon A \& Mazari L (2002) Nutrition and ageing of the immune system. In Nutrition and Immune Function, pp. 357-374 [PC Calder, CJ Field and HS Gill, editors]. Oxford: CABI Publishing.

Levy SM, Herberman RB, Lee J, Whiteside T, Beadle M, Heiden L \& Simons A (1991) Persistently low natural killer cell activity, age, and environmental stress as predictors of infectious morbidity. Nat Immun Cell Growth Regul 10, 289-307.

Liebmann PM, Reibnegger G, Lehofer M, Moser M, Purstner P, Mangge H \& Schauenstein K (1998) Circadian rhythm of the soluble p75 tumor necrosis factor (sTNF-R75) receptor in humans - a possible explanation for the circadian kinetics of TNF- $\alpha$ effects. Int Immunol $\mathbf{1 0}$, $1393-1396$

Liew FY (2002) T(H)1 and T(H)2 cells: a historical perspective. Nature Rev Immunol 2, 55-60.

Ligthart GJ, Corberand JX, Fournier C, Galanaud P, Hijmans W, Kennes B, Muller-Hermelink HK \& Steinmann GG (1984) Admission criteria for immunogerontological studies in man: the SENIEUR protocol. Mech Ageing Dev 28, 47-55.

Lord JM, Butcher S, Killampali V, Lascelles D \& Salmon M (2001) Neutrophil ageing and immunesenescence. Mech Ageing Dev 122, 1521-1535.

Lyons AB (2000) Analysing cell division in vivo and in vitro using flow cytometric measurement of CFSE dye dilution. J Immunol Methods 243, 147-154.

Mackinnon LT (1999) Advances in Exercise and Immunology. Champaign, IL: Human Kinetics.

MacLean LD (1988) Delayed type hypersensitivity testing in surgical patients. Surg Gynecol Obstet 166, 285-293.

MacLennan ICM \& Drayson MT (1999) Normal lymphocytes and nonneoplastic lymphocyte disorders. In Postgraduate Haematology, 4th ed., pp. 296-298 [AV Hoffbrand, SM Lewis and EGD Tuddenham, editors]. Oxford: Butterworth Heinemann.

Maloy KJ \& Powrie F (2001) Regulatory T cells in the control of immune pathology. Nat Immunol 2, 816-822.

Maloy KJ, Salaun L, Cahill R, Dougan G, Saunders NJ \& Powrie F (2003) $\mathrm{CD} 4{ }^{+} \mathrm{CD} 25^{+} \mathrm{T}(\mathrm{R})$ cells suppress innate immune pathology through cytokine-dependent mechanisms. J Exp Med 197, 111-119.

Mann DR, Akinbami MA, Gould KG \& Ansari AA (2000) Seasonal variation in cytokine expression and cell-mediated immunity in male rhesus monkeys. Cell Immunol 200, 105-115.

Marrie TJ, Johnson S \& Durant H (1988) Cell-mediated immunity of healthy adult Nova Scotians in various age groups compared with nursing home and hospitalized senior citizens. J Allergy Clin Immunol 81, 836-843.

Martinon F, Rabian C, Loiseau P, Ternynck T, Avrameas S \& Colombani J (1987) In vitro proliferation of human lymphocytes measured by an enzyme immunoassay using an anti-5-bromo-2-deoxyuridine monoclonal antibody. J Clin Lab Immunol 23, 153-159.

Matthews CE, Ockene IS, Freedson PS, Rosal MC, Merriam PA \& Hebert JR (2002) Moderate to vigorous physical activity and the risk of upperrespiratory tract infection. Med Sci Sports Exerc 34, 1242-1248.

Mazari L \& Lesourd B (1998) Nutritional influence on immune response in healthy aged persons. Mech Ageing Dev 100, 17-32. 
Messele T, Roos MT, Hamann D, Koot M, Fontanet AL, Miedema F, Schellekens PT \& Rinke de Wit TF (2000) Nonradioactive techniques for measurement of in vitro $\mathrm{T}$-cell proliferation: alternatives to the $\left[{ }^{3} \mathrm{H}\right]$ thymidine incorporation assay. Clin Diagn Lab Immunol 7, 687-692.

Meyaard L, Kuiper H, Otto SA, Wolthers KC, van Lier RA \& Miedema F (1995) Evidence for intact costimulation via CD28 and CD27 molecules in hyporesponsive $\mathrm{T}$ cells from human immunodeficiency virus-infected individuals. Eur J Immunol 25, 232-237.

Meydani SN, Barklund MP, Liu S, Meydani M, Miller RA, Cannon JG, Morrow FD, Rocklin R \& Blumberg JB (1990) Vitamin E supplementation enhances cell-mediated immunity in healthy elderly subjects. Am $J$ Clin Nutr 52, 557-563.

Meydani SN, Meydani M, Blumberg JB, Lekal S, Siber G, Loszewski R, Thompson C, Pedrosa C, Diamond RD \& Stollar BD (1997) Vitamin E supplementation and in vivo immune responses in healthy elderly individuals. JAMA 277, 1380-1386.

Moynihan JA, Callahan TA, Kelley SP \& Campbell LM (1998) Adrenal hormone modulation of type 1 and type 2 cytokine production by spleen cells: dexamethasone and dehydroepiandrosterone suppress interleukin-2, interleukin-4, and interferon-gamma production in vitro. Cell Immunol 184, 58-64.

Murasko DM, Weiner P \& Kaye D (1987) Decline in mitogen induced proliferation of lymphocytes with increasing age. Clin Exp Immunol 70, 440-448.

Mylonaki M, Fritscher-Ravens A \& Swain P (2003) Wireless capsule endoscopy: a comparison with push enteroscopy in patiens with gastroscopy and colonoscopy negative gastrointestinal bleeding. Gut 52, $1122-1126$.

Myrianthefs P, Karatzas S, Venetsanou K, Grouzi E, Evagelopoulou P, Boutzouka E, Fildissis G, Splilotopoulou I \& Baltopoulos G (2003) Seasonal variation in whole blood cytokine production after LPS stimulation in normal individuals. Cytokine 24, 286-292.

Nagao F, Yabe T, Xu M, Yokoyama K, Saito K \& Okumura K (1996) Application of non-radioactive europium $\left(\mathrm{Eu}^{3+}\right)$ release assay to a measurement of human natural killer activity of healthy and patient populations. Immunol Invest 25, 507-518.

Nelson RJ (2004) Seasonal immune function and sickness responses. Trends Immunol 25, 187-192.

Nelson RJ \& Demas GE (1996) Seasonal changes in immune function. $Q$ Rev Biol 71, 511-548.

Nieman DC (1994) Exercise, infection and immunity. Int J Sports Med 15, S131-S141.

Nieman DC, Johansen LM, Lee JW \& Arabatzis K (1990) Infectious episodes in runners before and after the Los Angeles Marathon. J Sports Med Phys Fitness 30, 316-328.

Niess AM, Dickhuth H-H, Northoff H \& Fehrenbach E (1999) Free radicals and oxidative stress in exercise - immunological aspects. Exerc Immunol Rev 5, 22-56.

Nisbet-Brown ER, Lee JW, Cheung RK \& Gelfand EW (1987) Antigenspecific and -nonspecific mitogenic signals in the activation of human $\mathrm{T}$ cell clones. J Immunol 138, 3713-3719.

Northoff H, Berg A \& Weinstock C (1998) Similarities and differences of the immune response to exercise and trauma: the IFN- $\gamma$ concept. Can J Physiol Pharmacol 76, 497-504.

O'Gorman MRG (2002) Evaluation of phagocytic cell function. In Manual of Clinical Laboratory Immunology, 6th ed., pp. 265-273 [NR Rose, B Hamilton and B Detrick, editors]. Washington, DC: ASM Press.

Ogata K, An E, Shioi Y, Nakamura K, Luo S, Yokose N, Minami S \& Dan K (2001) Association between natural killer cell activity and infection in immunologically normal elderly people. Clin Exp Immunol 124, 392-397.

Ouellette AJ \& Bevins CL (2000) Development of innate immunity in the small intestine. In Development of the Gastrointestinal Tract, pp. 147-164 [IR Sanderson and WA Walker, editors]. Hamilton, BC: Decker.
Paavonen T (1994) Hormonal regulation of immune responses. Ann Med 26, 255-258.

Pallast EG, Schouten EG, De Waart FG, Fonk HC, Doekes G, von Blomberg BM \& Kok FJ (1999) Effect of 50- and 100-mg vitamin E supplements on cellular immune function in noninstitutionalized elderly persons. Am J Clin Nutr 69, 1273-1281.

Pawelec G, Barnett Y, Forsey R, et al. (2002) T cells and aging, January 2002 update. Front Biosci 1, 1056-1283.

Pawelec G, Akbar A, Caruso C, Effros R, Grubeck-Loebenstein B \& Wikby A (2004) Is immunosenescence infectious? Trends Immunol 25, 406-410.

Pedersen BK \& Bruunsgaard H (1995) How physical exercise influences the establishment of infections. Sports Med 19, 393-400.

Peters EM \& Bateman ED (1983) Ultramarathon running and URTI: an epidemiological survey. S A Med J 64, 582-584.

Peters EM, Goetzsche JM, Grobbelaar B \& Noakes TD (1993) Vitamin C supplementation reduces the incidence of post-race symptoms of upper respiratory tract infection in ultramarathon runners. Am J Clin Nutr 57, 170-174.

Peters EM, Goetzsche JM, Joseph LE \& Noakes TD (1996) Vitamin C as effective as combinations of anti-oxidant nutrients in reducing symptoms of upper respiratory tract infections in ultramarathon runners. $S$ A J Sports Med 11, 23-27.

Petersen EW \& Pedersen BK (2002) Exercise and immune function. In Nutrition and Immune Function, pp. 347-355 [PC Calder, CJ Fields and HS Gill, editors]. Oxford: CABI Publishing.

Provinciali M, Di Stefano G \& Fabris N (1992) Optimization of cytotoxic assay by target cell retention of the fluorescent dye carboxyfluorescein diacetate (CFDA) and comparison with conventional ${ }^{51} \mathrm{Cr}$ release assay. J Immunol Methods 155, 19-24.

Pyne DB (1994) Regulation of neutrophil function during exercise. Sports Med 17, 245-258.

Remick DG (2002) Protein analysis and bioassays of cytokines and cytokine receptors. In Manual of Clinical Laboratory Immunology, 6th ed., pp. 320-337 [NR Rose, B Hamilton and B Detrick, editors]. Washington, DC: ASM Press.

Renshaw M, Rockwell J, Englemann C, Gerwirtz A, Katz J \& Sambhara S (2002) Cutting edge: impaired toll-like receptor expression and function in aging. J Immunol 169, 4697-4701.

Robson PJ, Blannin AK, Walsh NP, Castell LM \& Gleeson M (1999) Effects of exercise intensity, duration and recovery on in vitro neutrophil function in male athletes. Int J Sports Med 20, 128-135.

Roller M, Rechkemmer G \& Watzl B (2004) Prebiotic inulin enriched with oligofructose in combination with the probiotics Lactobacillus rhamnosus and Bifidobacterium lactis modulates intestinal immune functions in rats. $J$ Nutr 134, 153-156.

Ronsen O, Pedersen BK, Oritsland TR, Bahr R \& Kjeldsen-Kragh J (2001) Leukocyte counts and lymphocyte responsiveness associated with repeated bouts of strenuous endurance exercise. J Appl Physiol 91, 425-434.

Samartin S \& Chandra RK (2001) Obesity, overnutrition and the immune system. Nutr Rev 21, 243-262.

Sapolsky RM, Krey LC \& McEwen BS (1986) The neuroendocrinology of stress and aging: the glucocorticoid cascade hypothesis. Endocr Rev 7, 284-301.

Schellekens PT, Roos MT, De Wolf F, Lange JM \& Miedema F (1990) Low T-cell responsiveness to activation via CD3/TCR is a prognostic marker for acquired immunodeficiency syndrome (AIDS) in human immunodeficiency virus-1 (HIV-1)-infected men. J Clin Immunol 10, 121-127.

Schnare M, Barton GM, Holt AC, Takeda K, Akira S \& Medzhitov R (2001) Toll-like receptors control activation of adaptive immune responses. Nat Immunol 2, 947-950.

Scrimshaw NS \& SanGiovanni JP (1997) Synergism of nutrition, infection and immunity: an overview. Am J Clin Nutr 66, 464S-477S.

Shephard RJ (1997) Physical Activity, Training and the Immune Response. Carmel, IN: Cooper. 
Shephard RJ \& Shek PN (1999) Effects of exercise and training on natural killer cell counts and cytolytic activity: a meta-analysis. Sports Med $\mathbf{2 8}$, $177-195$.

Sherman AR (1992) Zinc, copper and iron nutriture and immunity. J Nutr 122, 604-609.

Sleijffers A, Garssen J, de Gruijl FR, Boland GJ, van Hattum J, van Vloten WA \& van Loveren H (2001) Influence of ultraviolet B exposure on immune responses following hepatitis B vaccination in human volunteers. J Invest Dermatol 117, 1144-1150.

Smith DS, Helzner EC, Nuttall CE Jr, Collins M, Rofman BA, Ginsberg D, Goswick CB \& Magner A (1989) Failure of zinc gluconate in treatment of upper respiratory tract infections. Antimicrob Agents Chemother 33, 646-648.

Smith JK, Chi DS, Krish G, Reynolds S \& Cambron G (1990) Effect of exercise on complement activity. Ann Allergy 65, 304-310.

Spirer Z, Roifman CM \& Branski D (1993) Pediatric Immunology. Pediatric and Adolescent Medicine, vol. 3. Basel: Karger.

Starkie RL, Rolland J, Angus DJ, Anderson MJ \& Febbraio M (2001) Circulating monocytes are not the source of elevations in plasma IL-6 and TNF- $\alpha$ levels after prolonged running. Am J Physiol Cell Physiol 280, C769-C774.

Steensberg A, van Hall G, Osada T, Sacchetti M, Saltin B \& Pedersen BK (2000) Production of interleukin-6 in contracting human skeletal muscles can account for the exercise-induced increase in plasma interleukin-6. J Physiol 529, 237-242.

Swain P (2003) Wireless capsule: endoscopy. Gut 52, Suppl. 4, 48-50.

Tacket CO, Binion SB, Bostwick E, Losonsky G, Roy MJ \& Edelman R (1992) Efficacy of bovine milk immunoglobulin concentrate in preventing illness after Shigella flexneri challenge. Am J Trop Med Hyg 47, 276-283.

Tollerud DJ, Morris Brown L, Clark JW, Neuland CY, Mann DL, PankiwTrost LK \& Blattner WA (1991) Cryopreservation and long-term liquid nitrogen storage of peripheral blood mononuclear cells for flow cytometry analysis: effects on subsets proportions and fluorescence intensity. J Clin Lab Anal 5, 255-261.

Touloumi G, Pantazis N, Karafoulidou A, Mandalaki T, Goedert JJ, Kostrikis LG \& Hatzakis A (2004) Changes in T cell receptor excision DNA circle (TREC) levels in HIV type 1-infected subjects pre- and post-highly active antiretroviral therapy. AIDS Res Hum Retroviruses 20, $47-54$.

Turner RB \& Cetnarowski WE (2000) Effect of treatment with zinc gluconate or zinc acetate on experimental and natural colds. Clin Infect Dis 31, 1202-1208.

Turner RB, Riker DK \& Gangemi JD (2000) Ineffectiveness of echinacea for prevention of experimental rhinovirus colds. Antimicrob Agents Chemother 44, 1708-1709.

Van Loveren H, Germolec D, Koren HS, Luster MI, Nolan C, Repetto R, Smith E, Vos JG \& Vogt RF (1999) Report of the Bilthoven Symposium: Advancement of epidemiological studies in assessing the human health effects of immunotoxic agents in the environment and the workplace. Biomarkers 4, 135-157.
Van Loveren H, Van Amsterdam JG, Vandebriel RJ, Kimman TG, Rumke HC, Steerenberg PS \& Vos JG (2001) Vaccine-induced antibody responses as parameters of the influence of endogenous and environmental factors. Environ Health Perspect 109, 757-764.

Verde TJ, Thomas SG, Moore RW, Shek P \& Shephard RJ (1992) Immune responses and increased training of the elite athlete. $J$ Appl Physiol 73, 1494-1499.

Vignali DA (2000) Multiplexed particle-based flow cytometric assays. $J$ Immunol Methods 243, 243-255.

Walker LS (2004) $\mathrm{CD} 4{ }^{+} \mathrm{CD} 25^{+}$Treg: divide and rule? Immunology 111, 129-137.

Walrand S, Moreau K, Caldefie F, Tridon A, Chassagne J, Portefaix G, Cynober L, Beaufrère B, Vasson M-P \& Boirie Y (2001) Specific and nonspecific immune responses to fasting and refeeding differ in young adult and elderly persons. Am J Clin Nutr 74, 670-678.

Watzl B \& Watson RR (1992) Role of alcohol abuse in nutritional immunosuppression. $J$ Nut 122, 733-737.

Weksler ME (1995) Immune senescence: deficiency or dysregulation? Nutr Rev 53, Suppl., S1-S7.

Westermann J \& Pabst R (1990) Lymphocyte subsets in the blood: a diagnostic window on the lymphoid system? Immunol Today 11, 406-410.

Whiteside TL, Bryant J, Day R \& Herberman RB (1990) Natural killer cytotoxicity in the diagnosis of immune dysfunction: criteria for a reproducible assay. J Clin Lab Anal 4, 102-114.

Wiedermann U, Kundi M, Vollmann U, Kollaritsch H, Ebner C \& Wiedermann G (2000) Different HBs antibody versus lymphoproliferative responses after application of a monovalent (hepatitis B) or combined (hepatitis A + hepatitis B) vaccine. Int Arch Allergy Immunol 123, 349-353.

Wilder RL (1998) Hormones, pregnancy, and autoimmune diseases. Ann N Y Acad Sci 840, 45-50.

Wolf R (2004) Essential Pediatric Allergy, Asthma and Immunology. New York: McGraw-Hill.

Woods J, Lu Q, Ceddia MA \& Lowder T (2000) Special feature for the Olympics: effects of exercise on the immune system: exercise-induced modulation of macrophage function. Immunol Cell Biol 78, 545-553.

Yaqoob P, Newsholme EA \& Calder PC (1999) Comparison of cytokine production in cultures of whole human blood and purified mononuclear cells. Cytokine 11, 600-605.

Ye P \& Kirshner DE (2002) Measuring emigration of human thymocytes by T-cell receptor excision circles. Crit Rev Immunol 22, 483-497.

Zaman K, Baqui AH, Yunus M, Sack RB, Chowdhury HR \& Black RE (1997) Malnutrition, cell-mediated immune deficiency and acute upper respiratory infections in rural Bangladeshi children. Acta Paediatr 86, 923-927.

Zeidel A, Beilin B, Yardeni I, Mayburd E, Smirnov G \& Bessler H (2002) Immune response in asymptomatic smokers. Acta Anaesthesiol Scand 46, 959-964. 